Military Technical College

Kobry El-Kobba

Cairo, Egypt

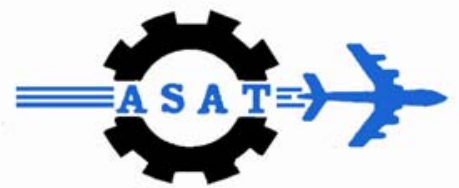

12-th International Conference

on

Aerospace Sciences \&

Aviation Technology

\title{
MOON PHASES AS GIS COMPUTER APPLICATION
}

\author{
Ibrahem zedan *, M. A. Soliman * and Basheer Nasef *
}

\begin{abstract}
In this paper, Moon phases will be investigated as a computer application in GIS. Moon phases depend on the position of moon and sun relative to the earth observation points. Objective of this study will be based on the following: (1) The concept of GIS and SDB, where the data measured to determine the moon phases have features as spatial data and can be treated as GIS. (2)The spatial data will be measured at any point on the surface of earth (local view), but all the data models as well as queries will be handled relative to the center of earth. The center of earth can be considered as the global point of view for all the spatial data of the moon phases. Therefore, a special transformation (direction cosine matrix) will be used to transform from local view to global view and vise versa. (3) The moon and sun position modeling which have a lot of work done during the history. The most recent model data will be used in this work.

As a result of this work, we can overcome the difficulties due to the local view. Crescent as one of the most critical moon phases is seen in some parts of the earth, and not others. Therefore in this paper we will try to determine the locus of points on earth surface which has the scene of the moon phases of the global view at earth center, i.e. the locus of points at the local view which has the same scene of moon phases as global view.
\end{abstract}

KEY WORDS:

Moon, Sun, Crescent Moon, Moon phases, Spatial Data Base (SDB), Geographic information system (GIS)

* Zaqaziq University 


\section{INTRODUCTION}

A few decades ago, paper maps were the principal means to synthesize and represent geographic information. Manipulating this information was limited to a manual, non-interactive process. Since then, the rapid development of new technologies to collect and digitize geographic data, together with an increasing demand for both interactive manipulation and analysis of this data, has generated a need for dedicated software, namely Geographic Information Systems (GIS s).[5]

The moon phases concerns data that is related to geographic scales of measurement, and is referenced by some coordinate system to locations on the surface of the earth. So it will be used as the computer application on GIS for this paper. Moon phases depend on the position of moon and sun relative to the earth observation points.

Spatial Data is data related to the space around us; data related to a location. Geographic information typically consists of data about time, space, and at least an attribute. Data are collected about a phenomenon and when it is at a particular time or how a phenomenon in a certain location changes over time. [4]

Spatial data in a GIS can be displayed just like a paper map with roads, rivers, and other features represented as lines on a map completed with legend, border and titles. Or it can be represented by a set of statistical tables, which can be converted to charts and graphs. The most important feature of GIS is that spatial data are stored in a structured format referred to as a spatial data base (SDB). [7]

Obliquity refers to the tilt of the Earth's axis. Over time, the angle of Earth's tilt varies between $\mathbf{2 2 . 2}$ and $\mathbf{2 4 . 5}$ degrees (currently the tilt is $\mathbf{2 3 . 5}$ and decreasing). These variations, discovered by French astronomer Urban Liverier in the 1840s, are caused by the gravitational pull of large planets, including Jupiter. Earth's obliquity varies cyclically with a period of 41,000 years as shown (Fig.1). [9]

Fig.2 shows that the Moon moves along the dotted path with respect to the Sun. Each day the Moon rises in the east and sets in the west as a result of the Earth's rotation. It moves about $13^{\circ}$ eastwards against the background of stars as a consequence of its revolution around the Earth. (GCSE Astronomy at "http://www.nmm.ac.uk/server/show/nav.00500300I005007002").

\section{SYSTEM MODEL:}

Before extracting any equations, it is known that the earth moves into two motions. The first is around itself, and the second is around the sun. The first motion completes one revolution every 23 h 56 m 4.091s (sidereal day), approximate 24 hours. The Second motion is through an elliptic orbit with Aphelion $=152500000 \mathrm{~km}$, Perihelion $=147500000$. This motion completes revolution every 365.24219 days (8766 hours) [3]. The moon moves around earth through also an elliptic orbit with Perigee $\left(363.3^{*} 10^{3} \mathrm{~km}\right)$, Apogee $\left(405.5^{*} 10^{3} \mathrm{~km}\right)$, and completes its revolution every 27.3217 days (i.e. a sidereal month which is defined as the time it takes for the moon to return to the same position relative to the stars). But the Syndic Period is 29.53 (days) (Syndics month is defined as the time it takes for the Moon to return to the same position relative to the Sun). 


\subsection{MOON MODEL}

The orbital elements of the Moon are shown in figures (3) and (4), and equation (1). The equations shown here are taken from Paul Schlyter's( "How to compute planetary positions" at http://stjarnhimlen.se/comp / ppcomp.html ).

$\begin{array}{ll}N=125.1228^{\circ}-0.0529538083^{\circ} d & \text { (Long asc. Node) } \\ I=5.1454^{\circ} & \text { (Inclination) } \\ w=318.0634^{\circ}+0.1643573223^{\circ} d & \text { (Arg. of perigee) } \\ a=60.2666 & \text { (Earth radii) } \\ e=0.054900 & \text { (Eccentricity) } \\ M=115.3654^{\circ}+13.0649929509^{\circ} d & \text { (Mean anomaly) }\end{array}$

Where $d \rightarrow$ Day Number. It can be computed from a JD (Julian Day Number) or

MJD (Modified Julian Day Number) like this:

$$
d=J D-2451543.5=M J D-51543.0
$$

-- $d$ can also be computed directly from the calendar date like this:

$$
\begin{aligned}
d= & 367 \text { Year }-(7(\text { Year }+(\text { mon }+9) / 12)) / 4+(275 \text { mon }) / 9+\text { day } \\
& -730530+(h / 24)
\end{aligned}
$$

In this formula all divisions should be INTEGER divisions. The mean distance, or semi-major axis, is expressed in earth equatorial radii), according to James $R$. Clynch 2006[1][6]

E, the eccentric anomaly is computed (This is an auxiliary angle used in Kepler's Equation, when computing the True Anomaly from the Mean Anomaly and the orbital eccentricity) by using Convergence of Newton's method [2][8].

$$
E 1=E 0-(E O-e \sin (E O)-M) /(1-e \cos (E O))
$$

Compute the Moon's distance and true anomaly. First compute the rectangular $(x, y)$ coordinates in the plane of the lunar orbit.

$$
\begin{aligned}
& x=R \cos (V)=a(\cos (E)-e) \\
& y=R \sin (V)=\left(a \sqrt{1-e^{2}}\right) \sin (E)
\end{aligned}
$$

-- Then convert this to distance and true anomaly as follow:

$$
\begin{aligned}
& R=\sqrt{X^{2}+y^{2}} \\
& V=\tan ^{-1}(Y / X)
\end{aligned}
$$

To compute the Moon's position in ecliptic coordinates, using the following formulae:

$$
\begin{aligned}
& \text { xeclip }=R(\cos (N) \cos (V+w)-\sin (N) \sin (V+w) \cos (i)) \\
& \text { yeclip }=R(\sin (N) \cos (V+w)+\cos (N) \sin (V+w) \cos (i)) \\
& \text { zeclip }=R \sin (V+w) \sin (i)
\end{aligned}
$$

--Then, convert them to ecliptic longitude, latitude, and distance. 
Azimuth_c $=\left\{\begin{array}{l}\tan ^{-1}(Y / X) \\ \text { or } \\ \cos ^{-1}\left(X / \sqrt{X^{2}+Y^{2}}\right)\end{array}\right.$

Elevation $c=\tan ^{-1}\left(Z / \sqrt{X^{2}+Y^{2}}\right)$

The big error in our computed lunar position results from ignoring the perturbations on the Moon. Below the most important perturbation terms are computed, and then added as corrections to previous computations. This may cut down the error to 1-2 arc minutes, or less. Several fundamental arguments will first be needed, such as:

Sun's mean longitude:

Moon's mean longitude:

Sun's mean anomaly:

Moon's mean anomaly:

Moon's mean elongation:

Moon's argument of latitude:

Now it's time to compute and add up the $\mathbf{1 2}$ largest perturbation terms in longitude, the $\mathbf{5}$ largest in latitude, and the $\mathbf{2}$ largest in distance as given below. For more detail see $\{$ App $A\}$

These perturbation terms are added to the ecliptic positions \{Longitude, Latitude and Mean distance\}. The ecliptic longitude and latitude is converted to rectangular coordinates $(x, y, z)$, and rotated through an angle corresponding to the obliquity of the ecliptic, then converted back to spherical coordinates. As described in \{App B1\}. Rectangular coordinates, longitude and latitude are stored into Spatial Data.

\subsubsection{Algorithm for compute moon position (see appendix $E$ for flow chart)}

- Initial date day $=25$, month $=6$, year $=2005$, hour $=3.5$

\section{First loop from 1 to 30}

-- An m-file (com_day.m) is written to evaluate Day Number (dd) by passing day, month, year and hour (UT). This function is based on eq (2) or eq (3).

$$
\text { dd = com_day(day, month, year, hour). }
$$

-- An m-file (moon1.m) is written to compute the moon position, azimuth, and Elevation at dd related to center of earth before adding any perturbations by Passing dd to the function. This file used eq (1) and from eq (4) to eq (9).

$[X m c(d), Y m c(d), Z m c(d), \operatorname{Azmc}(d), E I m c(d)]=\operatorname{moon1}(\boldsymbol{d d})$

-- An m-file (pert_lon .m) is written to compute perturbations in longitude

(degrees) by passing fundamental arguments $\left(L_{s}, L_{m}, M_{s}, M_{m}\right)$ to the function.

Pert_lon $(d)=$ pert_lon $\left(L_{s}, L_{m}, M_{s}, M_{m}\right)$

-- An m-file (Pert_lat. $\bar{m}$ ) is written to compute perturbations in latitude (degrees) by passing fundamental arguments $\left(L_{s}, L_{m}, M_{m}\right)$ to the function.

Pert_lat $(d)=$ pert_lat $\left(L_{s}, L_{m}, M_{m}\right)$

-- An m-file (Pert_lun.m) is written to compute perturbations in lunar distance (Earth radii) by passing fundamental arguments $\left(L_{s}, L_{m}, M_{m}\right)$ to the function.

Pert_lon (d) = pert_lon $\left(L_{s}, L_{m}, M_{m}\right)$

Then perturbations in longitude (Pert_lon(d)) are added to azimuth.

Perturbations in latitude (Pert_lat(d)) are added to elevation. 
Perturbations in lunar distance (Pert_lun(d)) are added to mean distance.

-- Convert the ecliptic longitude/latitude to rectangular coordinates $(x, y, z)$.

-- Rotate this $x, y, z$, system through an angle corresponding to the obliquity of the ecliptic, then convert back to spherical coordinates. As described in $\{A p p$ B1\}.

From Starry night program, the data measured are taken for moon and sun (azimuth \& elevation) at nine points (locations), which has (Longitude \& Latitude) on the surface of the earth as shown in (table 1.a) are considered. Such data are transformed to the center of earth. The data measured through one month (30 days), starting from $25 / 6 / 2005$ to $24 / 7 / 2005$ are recorded.

Table 1.a: Contains latitude and longitude for nine different locations on the earth's surface.

\begin{tabular}{||l|c|c|c|c|c|c|c|c|c|}
\hline Point Number & 1 & 2 & 3 & 4 & 5 & 6 & 7 & 8 & 9 \\
\hline Latitude $\phi$ & 30 & 30 & 45 & 45 & 45 & 30 & 15 & 15 & 15 \\
\hline Longitude $\lambda$ & 30 & 15 & 15 & 30 & 45 & 45 & 45 & 30 & 15 \\
\hline
\end{tabular}

These data were recorded at time $=3 \mathrm{~h}: 30 \mathrm{~m}$ : 00sec (AM/UT). Moon azimuth is saved in to mat-file as azim_moon [30][9]. Moon elevation is also saved in to mat-file as elem_moon [30][9]. Sun azimuth is saved in to mat-file as azim_sun [30][9]. Sun elevation is also saved in to mat-file as elem_sun [30][9].

Fig.5 shows Azimuth moon calculated (Azmc) vs. Azimuth moon measured (Azmm) after adding the most perturbations through 30 days in upper figure, while the error between them is in lower figure. The error is within $+0.03^{\circ}$ and $-0.06^{\circ}$. Fig. 6 shows Elevation moon calculated (EImc) vs. Elevation moon measured (Elmm) after adding the most perturbations through 30 days in upper figure, while the error between them is in lower figure. The error is within $+0.03^{\circ}$ and $-0.04^{\circ}$. (See also table $1 . b$ for spatial Database).

Table 1.b: Sample from Moon Azimuth and Elevation which are stored into SDB

\begin{tabular}{|c|c|c|c|c|c|c|}
\hline \multicolumn{7}{|c|}{ Moon Azimuth and Elevation (degree) } \\
\hline \multirow[b]{3}{*}{ Date } & \multirow{2}{*}{\multicolumn{2}{|c|}{$\frac{\text { Before add any }}{\text { perturbations }}$}} & \multirow{2}{*}{\multicolumn{2}{|c|}{ Measure }} & \multirow{2}{*}{\multicolumn{2}{|c|}{$\frac{\text { After adding the most }}{\text { perturbations }}$}} \\
\hline & & & & & & \\
\hline & Azim & Elev & Azim & Elev & Azim & Elev \\
\hline $25 / 6 / 05$ & 313.6411 & -268.192 & 319.4229 & -20.5073 & 319.3659 & -20.5413 \\
\hline $26 / 6 / 05$ & 328.3311 & -228.266 & 333.7499 & -14.9559 & 333.6921 & -14.98 \\
\hline $27 / 6 / 05$ & 342.851 & -173.972 & 346.9995 & -8.7126 & 346.9571 & -8.713 \\
\hline $28 / 6 / 05$ & 357.1235 & -109.576 & 359.4851 & -2.2059 & 359.4461 & -2.178 \\
\hline $29 / 6 / 05$ & 11.0975 & -39.8059 & 11.5294 & 4.256 & 11.4932 & 4.2751 \\
\hline $30 / 6 / 05$ & 24.7482 & 30.7156 & 23.462 & 10.3604 & 23.4205 & 10.3697 \\
\hline $1 / 7 / 05$ & 38.073 & 97.878 & 35.5518 & 15.8834 & 35.5065 & 15.8761 \\
\hline $2 / 7 / 05$ & 51.0864 & 158.307 & 48.012 & 20.6065 & 47.96 & 20.5865 \\
\hline $3 / 7 / 05$ & 63.8147 & 209.4305 & 60.9343 & 24.3292 & 60.8891 & 24.3041 \\
\hline $4 / 7 / 05$ & 76.2923 & 249.4382 & 74.2977 & 26.8794 & 74.2677 & 26.8507 \\
\hline $5 / 7 / 05$ & 88.5587 & 277.1869 & 87.9395 & 28.1046 & 87.9239 & 28.0928 \\
\hline $6 / 7 / 05$ & 100.6567 & 292.09 & 101.5784 & 27.9704 & 101.5746 & 27.9749 \\
\hline
\end{tabular}




\subsection{SUN MODEL}

To compute the sun position relative the center of earth, the orbital elements of the Sun are considered as follows:

$$
\begin{aligned}
& i=0^{\circ} \\
& \mathrm{W}_{\mathrm{s}}=282.9404^{\circ}+4.70935 \mathrm{E}-5^{\circ} d \\
& \mathrm{a}_{\mathrm{s}}=1.00000^{\circ} \\
& \mathrm{e}_{\mathrm{s}}=0.016709^{\circ}-1.151 \mathrm{E}-9^{\circ} d \\
& \mathrm{M}_{\mathrm{s}}=356.047^{\circ}+0.9856002585^{\circ} d
\end{aligned}
$$

(Inclination)

(longitude of perihelion)

(Mean distance, a.u.)

(Eccentricity)

(Mean anomaly)

The obliquity of the ecliptic, oblecl

$$
\text { Oblecl }=23.4393^{\circ}-3.563 \mathrm{E}-7^{\circ} d
$$

Where $d \rightarrow$ Day Number.

2.2.1 Algorithm for compute sun position (see appendix $E$ for flow chart)

i. Compute $d$ from (eq 2 or 3 ).

ii. Compute the eccentric anomaly $E$ by using (eq 4).

iii. Compute the Sun's distance and true anomaly from (eq 5). And then compute the longitude of the Sun.

$$
\text { Lon }=V_{s}+W_{s}
$$

iv. Last compute the Sun's ecliptic rectangular coordinates

$$
\begin{aligned}
& x_{s}=R_{s} \cos \text { (lon) } \\
& y_{s}=R_{s} \sin (\text { lon) } \\
& z_{s}=0.0
\end{aligned}
$$

v. Rotate these coordinates to equatorial coordinates, and then compute the Sun's

Azimuth and Elevation.\{App B1\}

$$
\begin{aligned}
& \text { Xequat }=x_{\mathrm{s}} \\
& \text { Yequat }=\cos \left(\text { oblecl) } y_{\mathrm{s}}+0.0 \sin (\text { oblecl })\right. \\
& \text { Zequat }=\sin (\text { oblecl }) y_{\mathrm{s}}+0.0 \cos (\text { oblecl })
\end{aligned}
$$

Note: All computations are related to $\mathrm{ECl}$ frame.

Fig.7 shows Azimuth sun calculated (Azsc) vs. Azimuth sun measured (Azsm) through 30 days in upper figure, while the error between them is in lower figure. Fig.8 shows Elevation sun calculated (Elsc) vs. Elevation sun measured (Elsm) through 30 days in upper figure, while the error between them is in lower figure. (See also table 2 for spatial Database). 
Table 2: Sample from Sun Azimuth and Elevation which are stored into SDB

\begin{tabular}{|c|c|c|c|c|}
\hline \multicolumn{5}{|c|}{ SUN Azimuth and Elevation (degree) } \\
\hline \multirow[b]{2}{*}{ Date } & \multicolumn{2}{|c|}{ Calculation } & \multicolumn{2}{|c|}{ Measure } \\
\hline & Azim & Elev & Azim & Elev \\
\hline $25 / 6 / 05$ & 94.0287 & 23.3869 & 94.0412 & 23.3921 \\
\hline 26/6/05 & 95.0673 & 23.3568 & 95.0738 & 23.3666 \\
\hline $27 / 6 / 05$ & 96.1052 & 23.3199 & 96.1144 & 23.3204 \\
\hline 28/6/05 & 97.1424 & 23.2761 & 97.1656 & 23.2847 \\
\hline 29/6/05 & 98.1788 & 23.2256 & 98.1991 & 23.2354 \\
\hline $30 / 6 / 05$ & 99.2143 & 23.1682 & 99.2308 & 23.1754 \\
\hline $1 / 7 / 05$ & 100.2488 & 23.1041 & 100.2619 & 23.1088 \\
\hline $2 / 7 / 05$ & 101.2822 & 23.0333 & 101.3034 & 23.0387 \\
\hline $3 / 7 / 05$ & 102.3145 & 22.9557 & 102.3267 & 22.9601 \\
\hline $4 / 7 / 05$ & 103.3455 & 22.8715 & 103.3592 & 22.8763 \\
\hline $5 / 7 / 05$ & 104.3752 & 22.7807 & 104.3734 & 22.7839 \\
\hline $6 / 7 / 05$ & 105.4035 & 22.6832 & 105.4241 & 22.6892 \\
\hline $7 / 7 / 05$ & 106.4303 & 22.5792 & 106.449 & 22.5939 \\
\hline $8 / 7 / 05$ & 107.4555 & 22.4687 & 107.4637 & 22.4772 \\
\hline $9 / 7 / 05$ & 108.479 & 22.3517 & 108.4959 & 22.3544 \\
\hline $10 / 7 / 05$ & 109.5009 & 22.2283 & 109.5178 & 22.2412 \\
\hline $11 / 7 / 05$ & 110.5209 & 22.0985 & 110.5406 & 22.1042 \\
\hline $12 / 7 / 05$ & 111.5391 & 21.9624 & 111.5633 & 21.9671 \\
\hline $13 / 7 / 05$ & 112.5553 & 21.82 & 112.5748 & 21.813 \\
\hline
\end{tabular}

\section{Moon Earth Sun model}

Linking between moon and sun systems is made and given the data mining from the system, therefore display these data on the world map and will be used it in other research. The idea of linking is for other phenomena, such as moon phases can be predicted based on the above results.

Determine location on the earth (Longitude and Latitude), with moon elevation approximate $=90^{\circ}$ at any time as a global view.

Expected moon image will be generated. This image will be processed at any point on the earth's surface. In order to get the model of the moon-earth-sun or in other words, the model of the moon phases, the following algorithm is used:

\subsection{Algorithm}

According to equations (1) to (14), The algorithm will be according to following steps:

1- Compute day number from eq (2) or eq (3).

2- Compute orbital moon elements at the same day eq (1).

3- Compute orbital sun elements using eq (10).

4- Compute true anomaly for both Moon and Sun using eq (6) and eq (12).

5- Compute and add all perturbations for the moon as in $\{\mathrm{App} A\}$.

6- Compute Cartesian coordinate system (3-D: X, Y, Z) for both the Moon and Sun from eq (14).

7- Transform from Cartesian coordinate $(X, Y, Z)$ to spherical coordinate $(R$, Azimuth, Elevation), as shown in $\{A p p B 1\}$.

8- Determine Moon phases based on Azimuth and Elevation for both the Moon and Sun. as shown in fig.(9), where each block in this fig. is explained in $\{$ App C 3$\}$.

For example, when the moon azimuth equal to sun azimuth, the moon is completely dark. From the point of view of the observer on the earth surface or earth center this moment defines the birth of the moon.

Fig.10 shows Sun azimuth, Sun elevation, Moon azimuth and Moon elevation related to the earth center from Moon and Sun Systems through 365 days.

The following notes can be deduced from (fig.10) 
- The earth moves through an elliptic orbit. This motion completes revolution every 365.24219 days. See sun azimuth curve.

- The moon moves through other an elliptic orbit, and completes its revolution every 27.3217 days (sidereal month). See moon azimuth curve.

- Sun elevation is within $\pm 23.5^{\circ}$ through 365 days (i.e. The obliquity of the ecliptic= $23.5^{\circ}$, see eq(3.14)).

- Moon elevation is within $\pm 28.5^{\circ}$ through 27.32 days (i.e. the moon moves in a plane inclined somewhat approximately $5.1454^{\circ}$ to the ecliptic).

Fig.11 shows Moon and Sun azimuth in the upper fig.for each day through 365 days, while Moon and Sun elevation are shown in lower figure.

The following note can be deduced from (fig.11)

- Moon azimuth curve intersects 12 times with Sun azimuth curve (i.e. $12 \mathrm{New}$ moon will be happened through 365 days (one year)).

\subsection{New \& Full Moon}

There is a moment when the moon comes in line with the sun and earth. This moment is called "New Moon Birth" (i.e. Moon azimuth = Sun azimuth) as shown in (Fig.12) and (Fig.13). At this moment sunlight will be falling on part of the moon facing the sun, and that facing earth will be completely dark. In other words new moon is "No Moon". No one can see this "New Moon" even by most powerful telescopes.

But, when earth comes in line with the sun and moon, this moment is called "Full Moon". At this moment of the moon facing earth is completely lighted. (i.e.: the difference between Moon Azimuth and Sun Azimuth is approximately $180^{\circ}$ at such moment) as shown in (Fig.14).

Therefore, to determine a new moon birth, draw moon azimuth vs. sun azimuth at the same time (related to the center of earth) based on the system in (Fig.9).

After determine a moment at which New moon is born, then using moon location at center to determine location on the surface of earth which has moon elevation $\cong 90^{\circ}$. Next determine full moon moment by drawing the difference between moon and sun azimuth, when the difference equal to $180^{\circ}$ (related to $\mathrm{ECl}$ ).

\subsection{SPATIAL DATA BASE}

A database system to store Cartesian coordinates System (3-D), Geographical data (longitude, latitude, azimuth and elevation), direction data (west, east, south and north) for moon and sun was created using a matlab program. Sample from tables are shown in Figures $(15-16)$.

\subsection{GIS from System model}

In this section, the link between spatial data and world map (GIS) is discussed in more detail. (Fig.17) shows location on the earth surface with moon elevation $=90^{\circ}$ at each hour through one day ( 10 / 7 / 2005) by using Universal Time (UT). While (fig.18) shows location on the earth surface has moon elevation $=90^{\circ}$ at each day through 28 day, starting from ( $25 / 6 / 2005)$ to $(22 / 7 / 2005)$, and (UT = 9h: 30m: 00s). for more detail see (fig.19). Location on the earth surface which with moon elevation $=90^{\circ}$ for each day at (UT $\left.=12 \mathrm{~h}: 30 \mathrm{~m}: 00 \mathrm{~s}\right)$ through 12 sidereal month as shown in (fig.20).

The following notes can be deduced from above figures (17 and 18) 
- The location on the earth surface with moon elevation $=90^{\circ}$ for each hour through one day is move from right to left (i.e. from east to west). Because the earth moves around itself.

- The location on the earth surface for each hour through one day is move from left to right (i.e. from west to east) looks like sine wave form. Because the earth moves around sun through an elliptic orbit.

Fig. 21 shows location on the earth surface with moon elevation $=90^{\circ}$ at crescent moon through 12 month.

\section{Summaries of Results}

The following facts and results can be deduced from linking between moon and sun systems:

- The obliquity of the ecliptic $=23.5^{\circ}$. While a plane of the moon inclined somewhat approximately $5.1454^{\circ}$ to the ecliptic.

- Spatial data base \{3-D, Azimuth, Elevation, phases, longitude, latitude, and time\} are stored into SDB. Therefore many queries can be obtained from SDB. Such that New moon full moon when? and so on.

- Moon phases can be deduced from intensity curves, Position of light on the moon surface and vice versa.

Transformation of any extracted data at the center of earth (global view) to any point on the surface (local view) is providing very good information in comparison to information from Starry night program and the astronomical Almanac. Ins, and U.S. Naval Observatory.

\section{REFERENCES}

[1] James R. Clynch; "Radius of the Earth - Radii Used in Geodesy". (available at www.//gmat.unsw.edu.au/snap/gps/clynch_pdfs/ radiigeo.pdf) (February 2006)

[2] A.J.Sakaii; "Remarks on Kepler's Equation". Electronic Journal of theoretical physics No 1:15-33 (2004)

[3] Boris S. Verkhovsky1" Amended Julian Worldwide Calendar". published in ANNALS of European Academy of Sciences, 2003, pp 334-338

[4] Bethell, Amber "Evaluating Conflicts in the Use and Development of Geographic Information Systems" Master of Science in Spatial Information Science and Eng., Dept-of Spatial Information Science and Eng., Maine University (2002). available at (http://www.library.umaine .edu/ theses/pdf/BethellA2002.pdf ).

[5] Philippe Rigaux, Michel Scholl, Agnes Voisard " Spatial Databases with Application to GIS" $2^{\text {nd }}$ edition, ISBN 1558605886, May 2001

[6] Katsuhiko Ogata, "Modern Control Engineering"; $3^{\text {rd }}$ Prentice Hall, 1997

[7] Melbourne, Australia; "What is a Geographic Information System?" Robert M. Itami and Robert J. Raulings, published by DLSR, 1993.

[8] Ilyas, Mohammad.(1984) "A Modern Guide to Astronomical Calculations of Islamic Calendar,Times, and Qibla, Berita" Berita Publishing Sdn. Bhd., Kula Lampur, 1984.

[9] University of Southern California (USC). Available at (http://earth.usc.edu / geol150/variability/orbitalchanges.html).

[10] Book of "Aerospace Avionics Systems Modern Synthesis" 


\section{Appendix A: Perturbations}

Perturbations in longitude (degrees):

$$
\begin{aligned}
& -1.274^{\circ} \sin \left(M_{m}-2 D\right) \\
& +0.658^{\circ} \sin (2 D) \\
& -0.186^{\circ} \sin \left(M_{s}\right) \\
& -0.059^{\circ} \sin \left(2 M_{m}-2 D\right) \\
& -0.057^{\circ} \sin \left(M_{m}-2 D+M_{s}\right) \\
& +0.053^{\circ} \sin \left(M_{m}+2 D\right) \\
& +0.046^{\circ} \sin \left(2 D-M_{s}\right) \\
& +0.041^{\circ} \sin \left(M_{m}-M_{s}\right) \\
& -0.035^{\circ} \sin (D) \\
& -0.031^{\circ} \sin \left(M_{m}+M_{s}\right) \\
& -0.015^{\circ} \sin (2 F-2 D) \\
& +0.011^{\circ} \sin \left(M_{m}-4 D\right)
\end{aligned}
$$

(Evection)

(Variation)

(Yearly equation)

(Parallactic equation)

Perturbations in latitude (degrees):

$$
\begin{aligned}
& -0.173^{\circ} \sin (F-2 D) \\
& -0.055^{\circ} \sin \left(M_{m}-F-2 D\right) \\
& -0.046^{\circ} \sin \left(M_{m}+F-2 D\right) \\
& +0.033^{\circ} \sin (F+2 D) \\
& +0.017^{\circ} \sin \left(2 M_{m}+F\right)
\end{aligned}
$$

Perturbations in lunar distance (Earth radii):

$-0.58 \cos \left(M_{m}-2 D\right)$

$-0.46 \cos (2 \mathrm{D})$

\section{Appendix B1: Convert the ecliptic longitude/latitude to rectangular coordinates} $(x, y, z)$.

\section{Then convert back to Spherical Coordinates.}

\section{Written by Paul Bourke} June 1996

There are three prevalent coordinate systems for describing geometry in 3 space, Cartesian, cylindrical, and spherical (polar). They all provide a way of uniquely defining any point in 3D.he following illustrates the three systems.

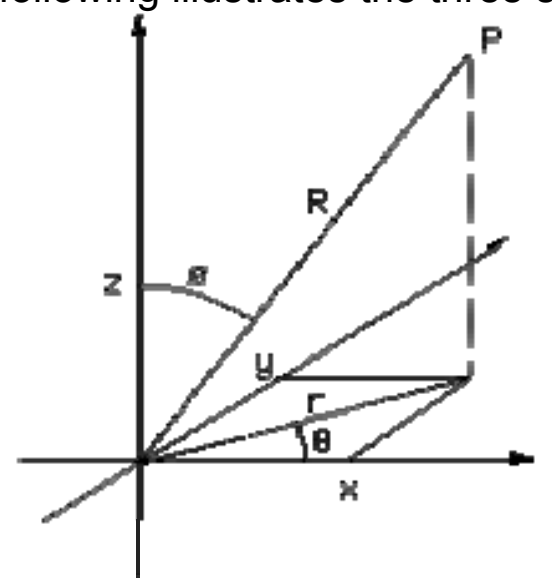

Equations for converting between Cartesian and cylindrical coordinates 


$\begin{array}{lll}z=z \cos (a) & x=\sqrt{x^{2}+y^{2}} & \sin (8)=y / \sqrt{x^{2}+y^{2}} \\ y=z \sin (\theta) & \theta=\arctan (y / x) & \cos (8)=x / \sqrt{x^{2}+y^{2}} \\ z=z & z=z & \end{array}$

Equations for converting between cylindrical and spherical coordinates

$$
\begin{array}{lll}
\mathrm{r}=\mathrm{R} \sin (\theta) & \mathrm{R}=\sqrt{\mathrm{r}^{2}+\mathrm{z}^{2}} & \sin (\theta)=\mathrm{r} / \sqrt{\mathrm{r}^{2}+z^{2}} \\
\mathrm{z}=\mathrm{R} \cos (\theta) & \theta=\arctan (\mathrm{r} / z) & \cos (\theta)=z / \sqrt{\mathrm{r}^{2}+z^{2}} \\
\mathrm{\theta}=\mathrm{\theta} & \mathrm{\theta}=\mathrm{\theta} &
\end{array}
$$

Equations for converting between Cartesian and spherical coordinates

$$
\begin{array}{ll}
x=\mathrm{R} \sin (\theta) \cos (\theta) & \mathrm{R}=\sqrt{x^{2}+y^{2}+z^{2}} \\
\mathrm{Y}=\mathrm{R} \sin (\theta) \sin (\theta) & \theta=\arctan (y / x) \\
\mathrm{z}=\mathrm{R} \cos (\theta) & \theta=\arctan \left(\sqrt{x^{2}+y^{2}} / z\right)
\end{array}
$$

\section{Rotation}

First rotation is made of the $(X, Y, Z)$ system about the $X$ axis through an angle $\phi$. This rotation is made in the positive, that is, anticlockwise sense. The rotation about $X$ of $\phi$ results in a new axes $\left(X^{\prime}, Y^{\prime}, Z^{\prime}\right)$ as shown below.

$$
\left(\begin{array}{l}
X^{\backslash} \\
Y^{\backslash} \\
Z^{\backslash}
\end{array}\right)=\left(\begin{array}{ccc}
1 & 0 & 0 \\
0 & \cos \phi & \sin \phi \\
0 & -\sin \phi & \cos \phi
\end{array}\right)\left(\begin{array}{l}
X \\
Y \\
Z
\end{array}\right)
$$

The second rotation about the $Y^{\prime}$ axis by the angle $\theta$. The coordinate transformation from the $\left(X^{\backslash}, Y^{\backslash}, Z^{\prime}\right)$-axis system to the new $\left(X^{\|}, Y^{\|}, Z^{\| \prime}\right)$ system is then given by

$$
\left(\begin{array}{l}
X^{\prime \prime} \\
Y^{\|} \\
Z^{\prime}
\end{array}\right)=\left(\begin{array}{ccc}
\cos \theta & 0 & -\sin \theta \\
0 & 1 & 0 \\
\sin \theta & 0 & \cos \theta
\end{array}\right)\left(\begin{array}{l}
X \\
Y^{\backslash} \\
Z^{\backslash}
\end{array}\right)
$$

Finally, the third rotation about the $Z^{\|}$axis by the angle $\psi$. The coordinate transformation from the $\left(X^{\|}, Y^{\|}, Z^{\|}\right)$axis system to the new $(x, y, z)$ system is then given by

$$
\left(\begin{array}{l}
x \\
y \\
z
\end{array}\right)=\left(\begin{array}{ccc}
\cos \psi & \sin \psi & 0 \\
-\sin \psi & \cos \psi & 0 \\
0 & 0 & 1
\end{array}\right)\left(\begin{array}{l}
X^{\prime \prime} \\
Y^{\prime \prime} \\
Z^{\prime \prime}
\end{array}\right)
$$


Appendix C2: Simulink model for simulating spatial observer for Sun and Moon Position \{OSP, OMP\}.

\section{Observer for Sun Position \{ OSP \}}

SUN_measurement

$$
\text { s_year1 }
$$
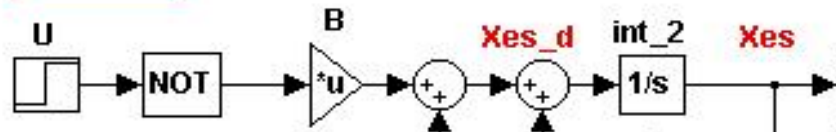

Model version 1.90

Ned May 24 19:09:26 2006

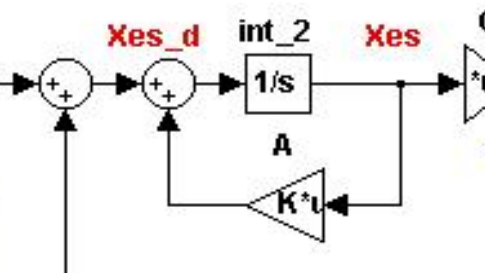
K*
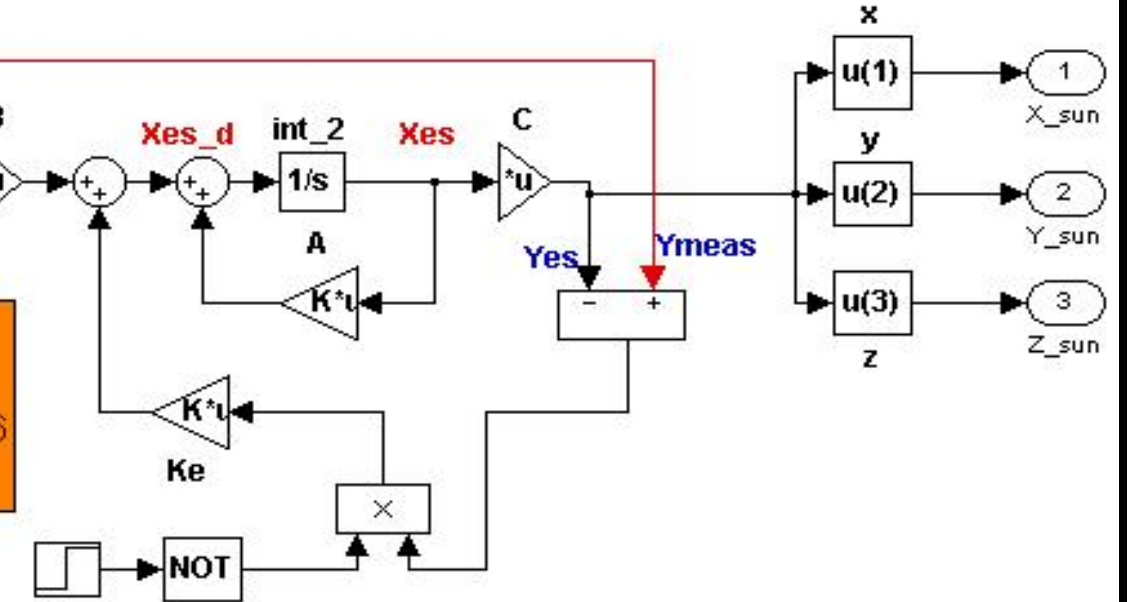

Fig.C2.1 Simulink model for simulating Spatial Observer Sun Position (OSP).

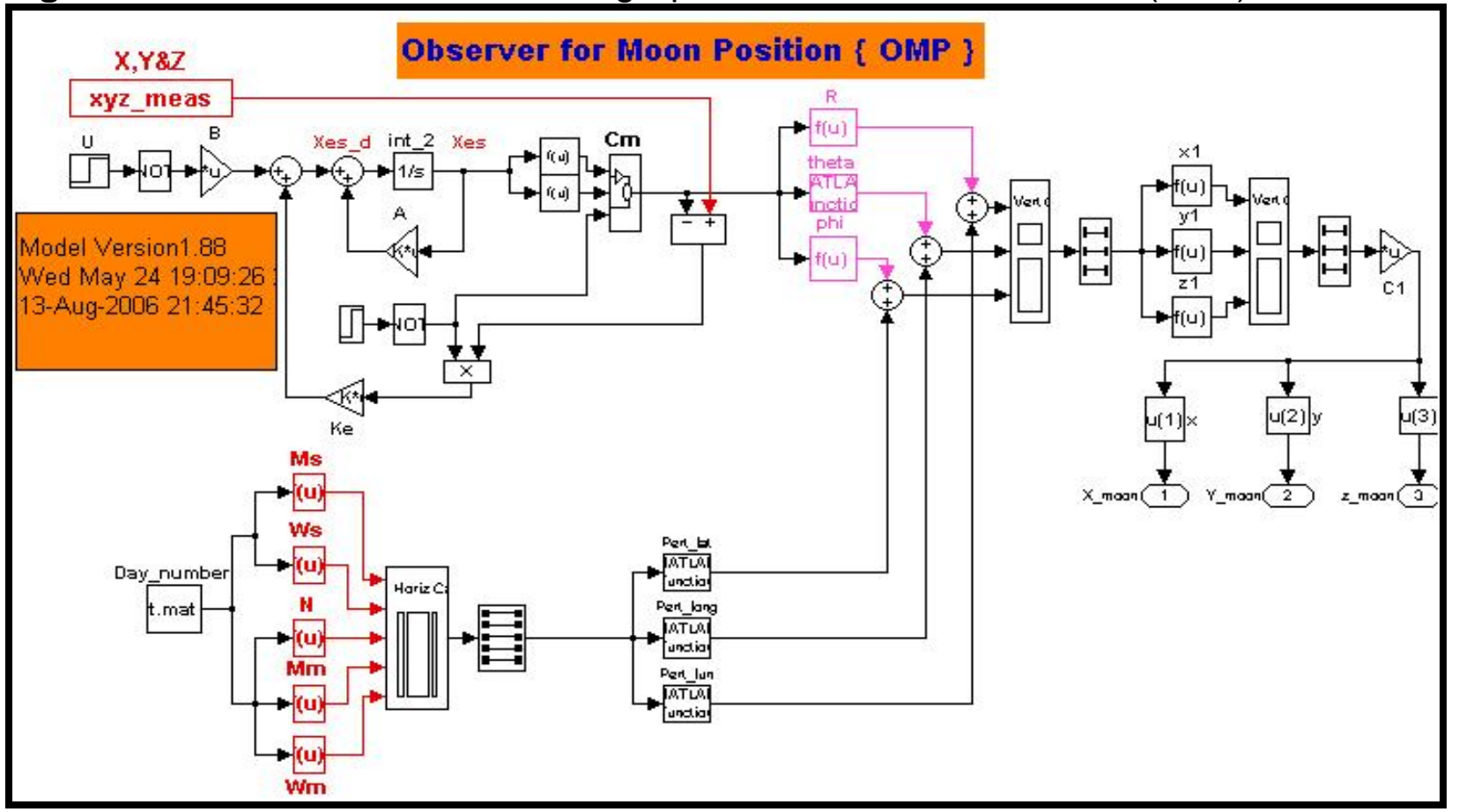

Fig.C2.2 Simulink model for simulating Spatial Observer Moon Position (OMP). 


\section{Appendix C3: Simulink model for determine location on the earth surface which has moon elevation $=90^{\circ}$.}

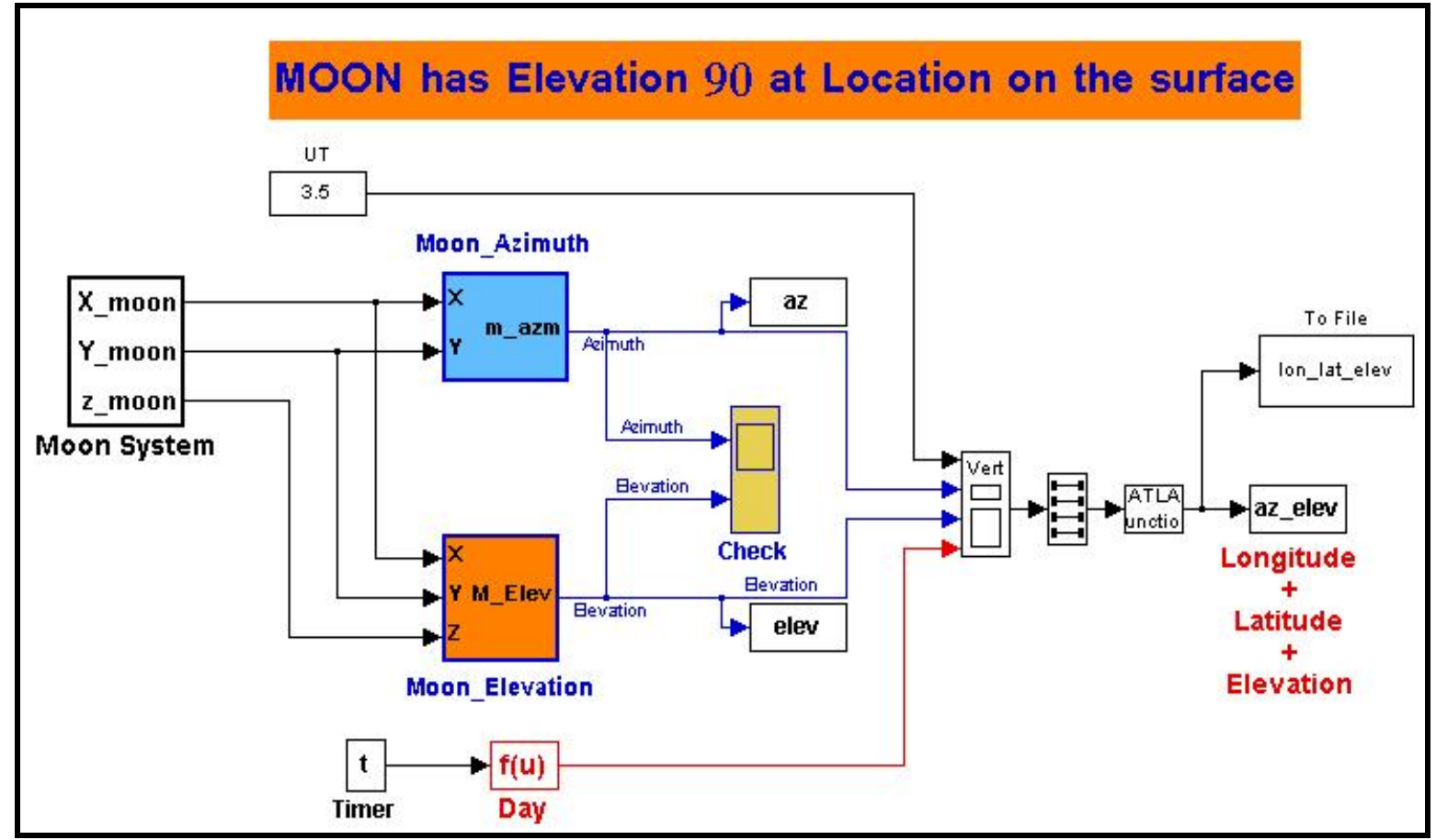

Fig.C3.1 Simulink model for simulating location on the earth surface which has moon elevation $=90^{\circ}$, based on OMP.

\section{Appendix D: Explaination of the matlab functions.}

\begin{tabular}{|c|c|}
\hline Function & Explanation \\
\hline moon_center & $\begin{array}{l}\text { Function [xeqm, yeqm, zeqm, mazc, melec]=moon_center(sec, min, } \\
\text { hour, day, mon, year) } \\
\% \text { This Function used to compute moon position related to the earth } \\
\% \text { center at any time ( Geocentric Positions ) i.e. as seen by an } \\
\text { imaginary observer at the center of the Earth. } \\
\% \text { USAGE: } \\
\% \text { sec --> Second, min --> Minute, hour --> Hour } \\
\% \text { day --> Day in month, mon --> Month number, year --> Year } \\
\text { number } \\
\% \text { which return : } \\
\% \text { xeqm, yeqm and zeqm --> are equatorial coordinates for the moon } \\
\% \text { mazc --> moon azimuth on the surface (degree) } \\
\% \text { melc --> moon elevation on the surface (degree) }\end{array}$ \\
\hline moon_surf & $\begin{array}{l}\text { Function [mazs, mels]= moon_surf (sec, min, hour, day, mon, year, } \\
\text { long, lat) } \\
\% \text { This Function used to compute moon position at any time } \\
\% \text { Apparent Topocentric Positions ( on the surface ) } \\
\% \text { USAGE: } \\
\% \text { sec --> Second, min --> Minute, hour --> Hour } \\
\% \text { day --> Day in month, mon --> Month number, year --> Year } \\
\text { number } \\
\% \text { long --> Longitude (degree) }\end{array}$ \\
\hline
\end{tabular}




\begin{tabular}{|c|c|}
\hline & $\begin{array}{l}\text { \% lat }-->\text { Latitude (degree) } \\
\% \text { which return: } \\
\% \text { mazs }-->\text { moon azimuth on the surface (degree) } \\
\% \text { mels }-->\text { moon elevation on the surface (degree) }\end{array}$ \\
\hline sun_center & $\begin{array}{l}\text { function [xeqs, yeqs, zeqs, sazc, selec]= sun_center (sec, min, hour, } \\
\text { day, mon, year) } \\
\% \text { This Function used to compute moon position related to the earth } \\
\text { center at \% any time ( Geocentric Positions ) } \\
\% \text { i.e. as seen by an imaginary observer at the center of the Earth. } \\
\% \text { USAGE: } \\
\% \text { sec --> Second, min --> Minute, hour --> Hour } \\
\% \text { day --> Day in month, mon --> Month number, year --> Year } \\
\text { number } \\
\% \text { which return : } \\
\% \text { xeqs, yeqs and zeqs --> are equatorial coordinates for the sun } \\
\% \text { sazc --> moon azimuth on the surface (degree) } \\
\% \text { selc --> moon elevation on the surface (degree) }\end{array}$ \\
\hline sun_surf & $\begin{array}{l}\text { Function [sazs, sels]= sun_surf (sec, min, hour, day, mon, year, long, } \\
\text { lat) } \\
\% \text { This Function used to compute sun position at any time } \\
\% \text { Apparent Topocentric Positions ( on the surface ) } \\
\% \text { USAGE: } \\
\% \text { sec --> Second, min --> Minute, hour --> Hour } \\
\% \text { day --> Day in month, mon --> Month number, year --> Year } \\
\text { number } \\
\% \text { long --> Longitude (degree) } \\
\% \text { lat --> Latitude (degree) } \\
\% \text { which return : } \\
\% \text { sazs --> sun azimuth on the surface (degree) } \\
\% \text { sels --> sun elevation on the surface (degree) }\end{array}$ \\
\hline moon_elev90 & $\begin{array}{l}\text { Function [longg, lat, mel]=moon_elev90(r, Ls, moon_az, declm, UT, } \\
\text { zz) } \\
\% \text { This Function used to Determine where location on the surface of } \\
\text { the earth which has elevation of the moon approximatly } 90 \\
\% \text { USAGE: } \\
\% \text { r --> Distance between moon and earth center } \\
\% \text { Ls --> the Sun's mean longitude } \\
\% \text { moon_az --> moon azimuth related to center (degree) } \\
\% \text { declm --> moon elevation related to center (degree) } \\
\% \text { UT --> Universal Time } \\
\% \text { zz --> Correction } \\
\% \text { which return : } \\
\% \text { long --> Longitude (degree) } \\
\% \text { lat --> Latitude (degree) } \\
\% \text { mel --> moon elevation on the surface (degree) }\end{array}$ \\
\hline Cen2surm & $\begin{array}{l}\text { Function [maz, mel]= Cen2surm(r, sidtime, lat, ram, declm) } \\
\% \text { This Function used to Transformation Moon position from Center } \\
\text { To } \\
\% \text { Any point on the surface of the earth. }\end{array}$ \\
\hline
\end{tabular}




\begin{tabular}{|c|c|}
\hline & $\begin{array}{l}\text { \% USAGE: } \\
\% \text { r =mean distance AU } \\
\% \text { sidtime =local time at location } \\
\% \text { Long }-->\text { Longitude (degree) } \\
\% \text { Lat --> Latitude (degree) } \\
\% \text { ram --> Moon azimuth at center (degree) } \\
\% \text { declm --> Moon elevation at center (degree) } \\
\% \text { which return: } \\
\% \text { maz --> Moon azimuth on the surface (degree) } \\
\% \text { mel --> Moon elevation on the surface (degree) }\end{array}$ \\
\hline cen2surs & $\begin{array}{l}\text { Function [saz, sel]= cen2surs(sidtime, long, lat, ra, decl) } \\
\% \text { This Function used to Transformation Sun position from Center To } \\
\% \text { Any point on the surface of the earth. } \\
\% \text { USAGE: } \\
\% \text { sidtime =local time at location } \\
\% \text { Long --> Longitude (degree) } \\
\% \text { Lat --> Latitude (degree) } \\
\% \text { ra --> Sun azimuth at center (degree) } \\
\% \text { decl --> Sun elevation at center (degree) } \\
\% \text { which return : } \\
\% \text { saz --> Sun azimuth on the surface (degree) } \\
\% \text { sel --> Sun elevation on the surface (degree) }\end{array}$ \\
\hline sur2cenm & $\begin{array}{l}\text { Function [mazc, melc]= sur2cenm(maz, mel, long, lat, r, sidtime) } \\
\% \text { This Function used to Transformation Moon position from } \\
\% \text { any point on the surface of the earth To Center. } \\
\% \text { USAGE: } \\
\% \text { maz --> Moon azimuth on the surface } \\
\% \text { mel --> Moon elevation on the surface } \\
\% \text { Long --> Longitude } \\
\% \text { Lat --> Latitude } \\
\% \text { r = mean distance AU } \\
\% \text { sidtime =local time at location } \\
\% \text { which return : } \\
\% \text { mazc --> Moon azimuth at center } \\
\% \text { melc --> Moon elevation at center }\end{array}$ \\
\hline sur2cens & $\begin{array}{l}\text { Function }[\mathrm{ra}, \text { decl] }=\text { sur2cens(saz, sel, lat, sidtime) } \\
\% \text { This Function used to Transformation from surface TO Center of } \\
\text { the earth } \\
\% \text { USAGE: } \\
\% \text { saz }=0-->360 \\
\% \text { sel }=-90090 \\
\% \text { lat }=(0: 90 \text { North }) \&(0:-90 \text { south })\end{array}$ \\
\hline com_day & $\begin{array}{l}\text { Function } d=c o m \_d a y(h, \text { day, mon, year) } \\
\% \text { This Function used to Compute Day Number. } \\
\% \text { Any division must be Integer Division except Hour/24 } \\
\% \text { USAGE: } \\
\% \text { Hour }=1-->24 \\
\% \text { Day }=\text { in the month from Date } \\
\% \text { Month }=1-->12\end{array}$ \\
\hline
\end{tabular}




\begin{tabular}{|c|c|}
\hline & $\begin{array}{l}\% \text { Year }=\text { four digits from Date } \\
\% \text { Examples: Date }=22 / 5 / 1989 \\
\% \quad \text { Day }=22, \text { Month }=5, \text { Year }=1989\end{array}$ \\
\hline azimuth & $\begin{array}{l}\text { Function az= azimuth }(x, y) \\
\% \text { This Function used to Compute Azimuth of any Planet. } \\
\% \text { USAGE: } \\
\% x-->\text { Coordinate } X \\
\% \text { y --> Coordinate } Y \\
\% \text { which return : } \\
\% \text { az }->\text { Azimuth }(0==>2 * P I \text { radian })\end{array}$ \\
\hline sid_time & $\begin{array}{l}\text { Function [sidtime,GMST0]= sid_time (Ls, UT, long) } \\
\% \text { This Function used to Compute Sidereal Time } \\
\% \text { [sidtime,GMSTO] = sid_time (Ls, UT, long) } \\
\% \text { USAGE: } \\
\% \text { Ls --> the Sun's mean longitude } \\
\% \text { UT --> Universal Time } \\
\% \text { long --> Longitude } \\
\% \text { which return : } \\
\% \text { sidtime --> a local time }\end{array}$ \\
\hline pert_lat & $\begin{array}{l}\text { Function per_lat }=\text { pert_lat (Ms, ws, N, Mm, w) } \\
\% \text { This Function used to Compute Perturbations in latitude } \\
\text { (degrees): } \\
\% \text { USAGE: } \\
\% \text { Ms --> (mean anomaly of the sun) } \\
\% \text { ws --> (longitude of perihelion) } \\
\% \mathrm{~N} \mathrm{-->} \mathrm{(Long} \mathrm{asc.} \mathrm{node)} \\
\% \mathrm{Mm} \mathrm{-->} \mathrm{(mean} \mathrm{anomaly} \mathrm{of} \mathrm{the} \mathrm{moon)} \\
\% \text { w --> (Arg. of perigee) } \\
\% \text { which return : } \\
\% \text { per_lat --> Perturbations in latitude (degrees) }\end{array}$ \\
\hline pert_lon & $\begin{array}{l}\text { Function per_lon = pert_lon (Ms, ws, N, Mm, w) } \\
\% \text { This Function used to Compute Perturbations in longitude } \\
\text { (degrees): } \\
\% \text { USAGE: } \\
\% \text { Ms --> (mean anomaly of the sun) } \\
\% \text { ws --> (longitude of perihelion) } \\
\% \mathrm{~N} \mathrm{-->} \mathrm{(Long} \mathrm{asc.} \mathrm{node)} \\
\% \mathrm{Mm} \mathrm{-->} \mathrm{(mean} \mathrm{anomaly} \mathrm{of} \mathrm{the} \mathrm{moon)} \\
\% \text { w --> (Arg. of perigee) } \\
\% \text { which return : } \\
\% \text { per_lon --> Perturbations in longitude (degrees) }\end{array}$ \\
\hline pert_lun & $\begin{array}{l}\text { Function per_lun = pert_lun (Ms, ws, } \mathrm{N}, \mathrm{Mm}, \mathrm{w}) \\
\% \text { This Function used to Compute Perturbations in lunar distance } \\
\text { (Earth radii): } \\
\% \text { USAGE: } \\
\% \mathrm{Ms} \mathrm{-->} \mathrm{(mean} \mathrm{anomaly} \mathrm{of} \mathrm{the} \mathrm{sun)} \\
\% \text { ws --> (longitude of perihelion) } \\
\% \mathrm{~N} \mathrm{-->} \mathrm{(Long} \mathrm{asc.} \mathrm{node)} \\
\% \mathrm{Mm} \mathrm{-->} \mathrm{(mean} \mathrm{anomaly} \mathrm{of} \mathrm{the} \mathrm{moon)}\end{array}$ \\
\hline
\end{tabular}




\begin{tabular}{|l|l|}
\hline & $\begin{array}{l}\text { \% w --> (Arg. of perigee) } \\
\text { \% which return : } \\
\text { \% per_lun --> Perturbations in lunar distance (Earth radii) }\end{array}$ \\
\hline col_curve & Function [mean1,intensity] = col_curve (img) \\
& $\%$ This Function used to Draw Intensity of light lie on Moon Image \\
& $\%$ Summations All Rows in the same Column \\
& $\%$ USAGE: \\
& $\%$ img --> (Moon Image) at any type \\
& $\%$ which return : \\
& $\%$ mean1 --> Average of Intensity \\
& $\%$ intensity --> Array of Intensity \\
\hline row_curve & function [mean1,intensity]= row_curve (img) \\
& $\%$ This Function used to Draw Intensity of light lie on Moon Image \\
& $\%$ Summations All Columns in the same Row \\
& $\%$ USAGE: \\
& $\%$ img --> (Moon Image) at any type \\
& $\%$ which return : \\
& $\%$ mean1 --> Average of Intensity \\
& $\%$ intensity --> Array of Intensity
\end{tabular}

Appendix E: Flow Chart for computing moon and Sun position see fig .23 and fig .24

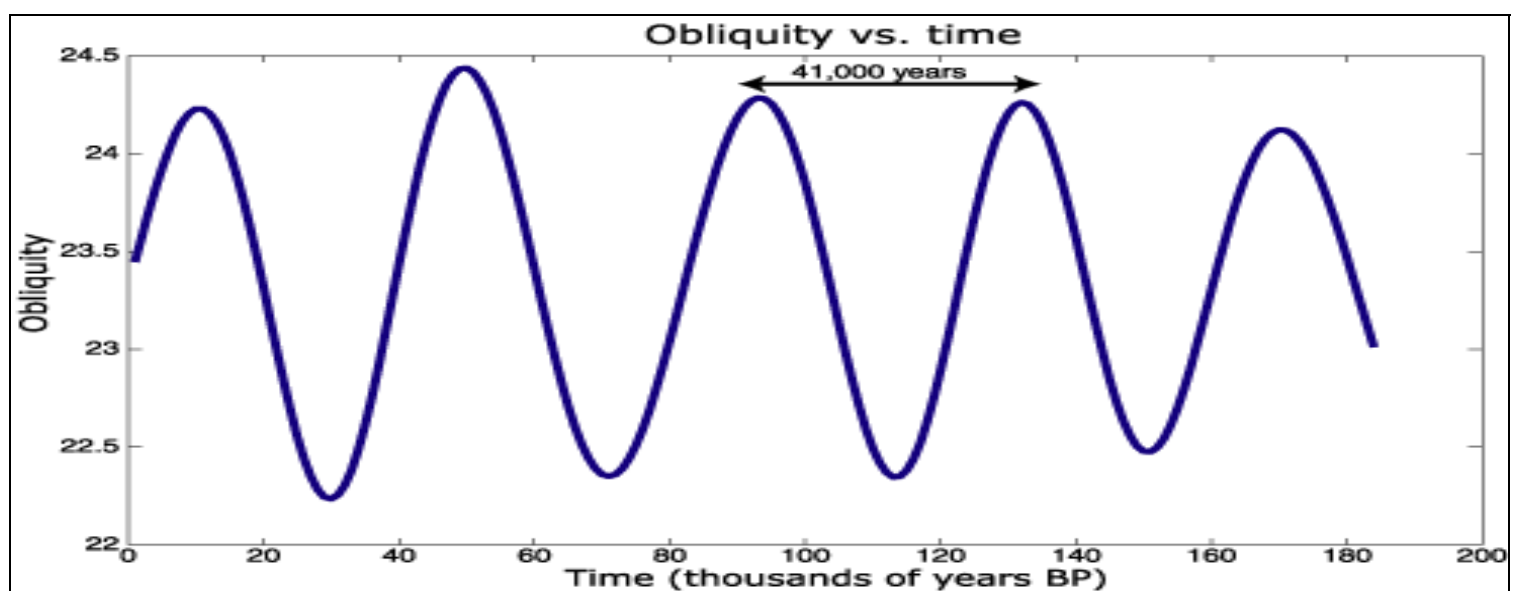

Fig. 1 obliquity of the earth 


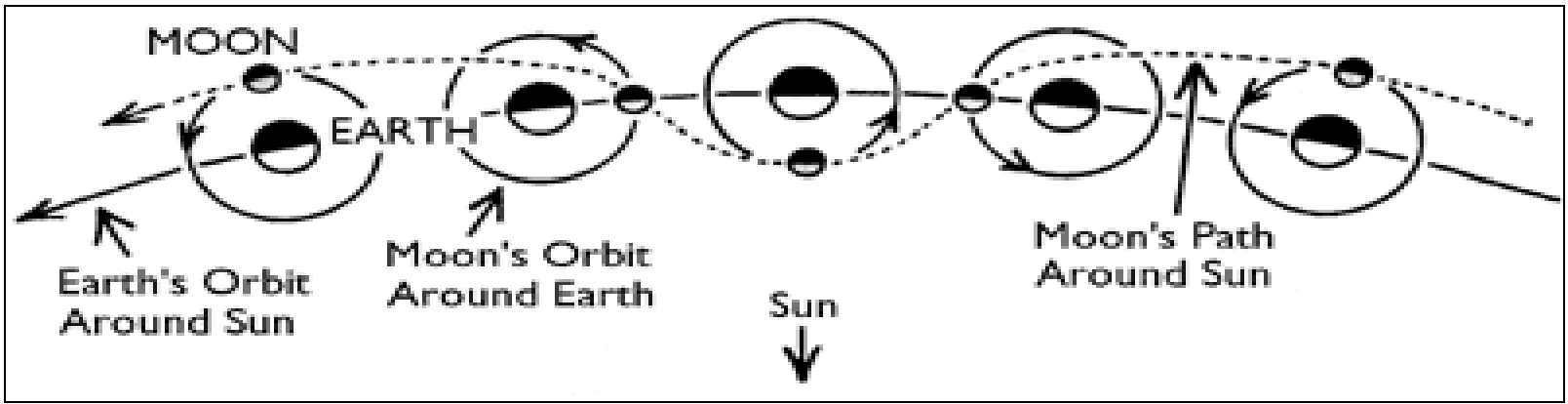

Fig. 2 Moon Motion

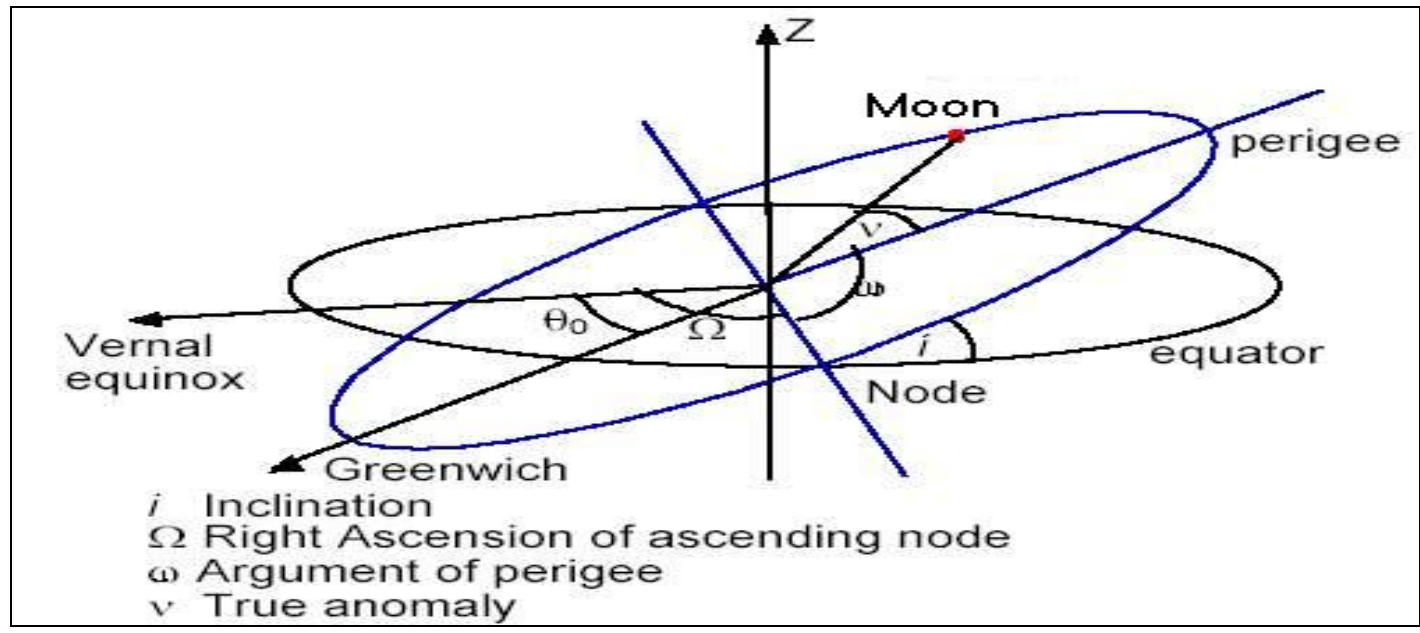

Fig. 3 : Moon orbital plane

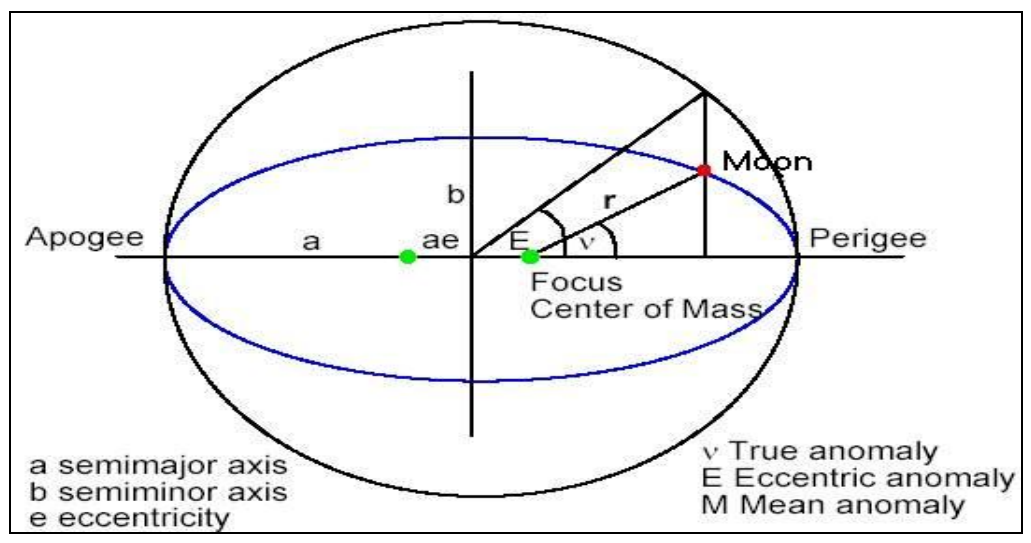

Fig. 4: Orbital elements of the moon 

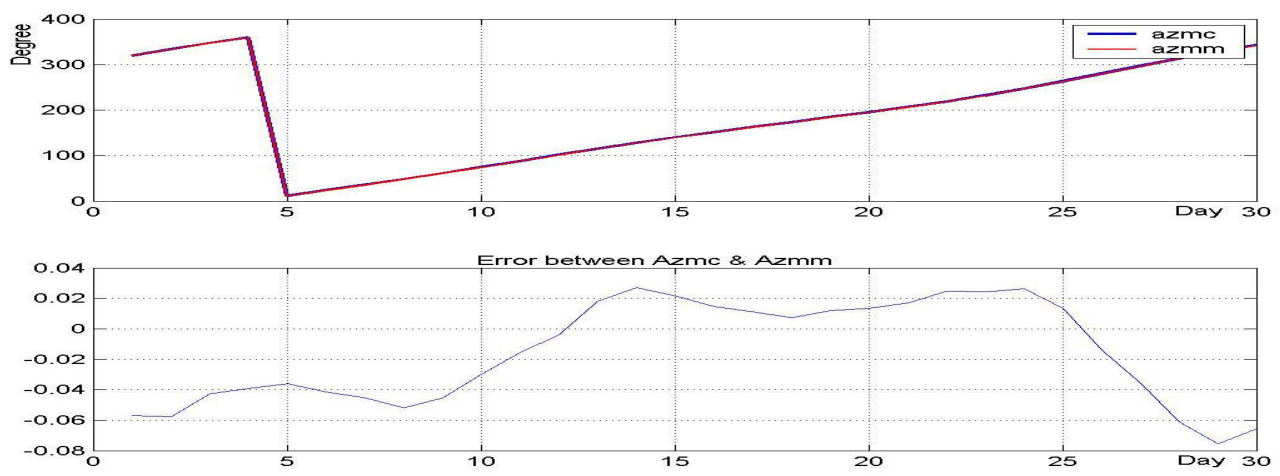

Fig.5 Azimuth moon calculated (Azmc) vs. Azimuth moon measured (Azmm) and the error between them.
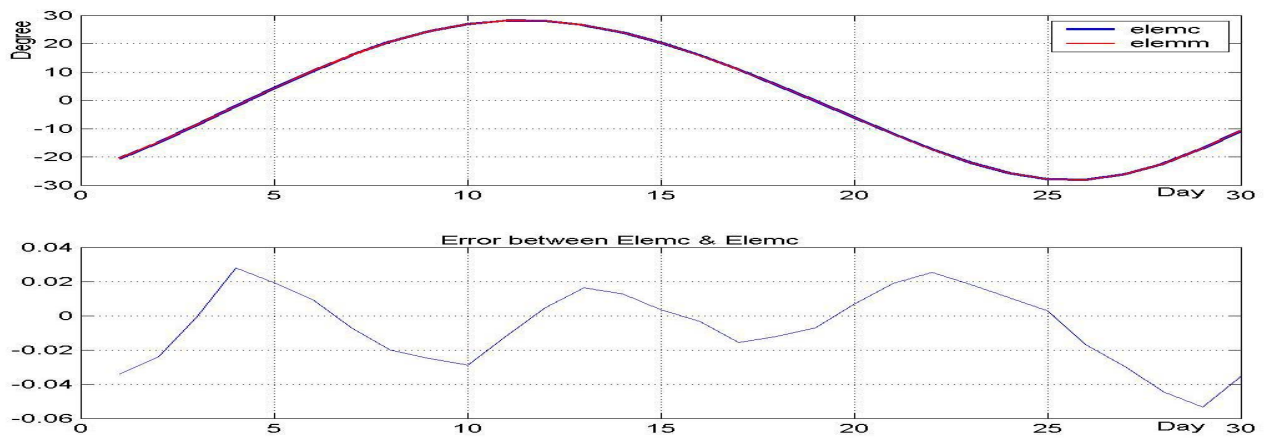

Fig.6 Elevation moon calculations (Elmc) vs. Elevation moon measurements (Elmm) and the error between them

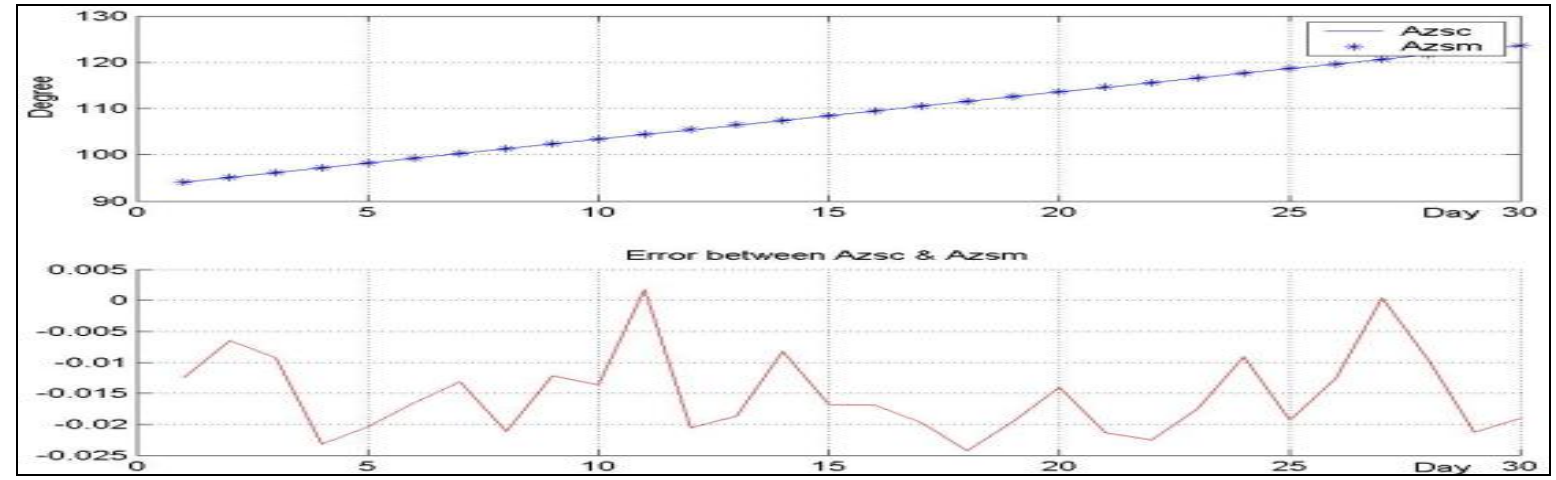

Fig.7 Azimuth sun calculated vs. Azimuth sun measured and the error between them. 


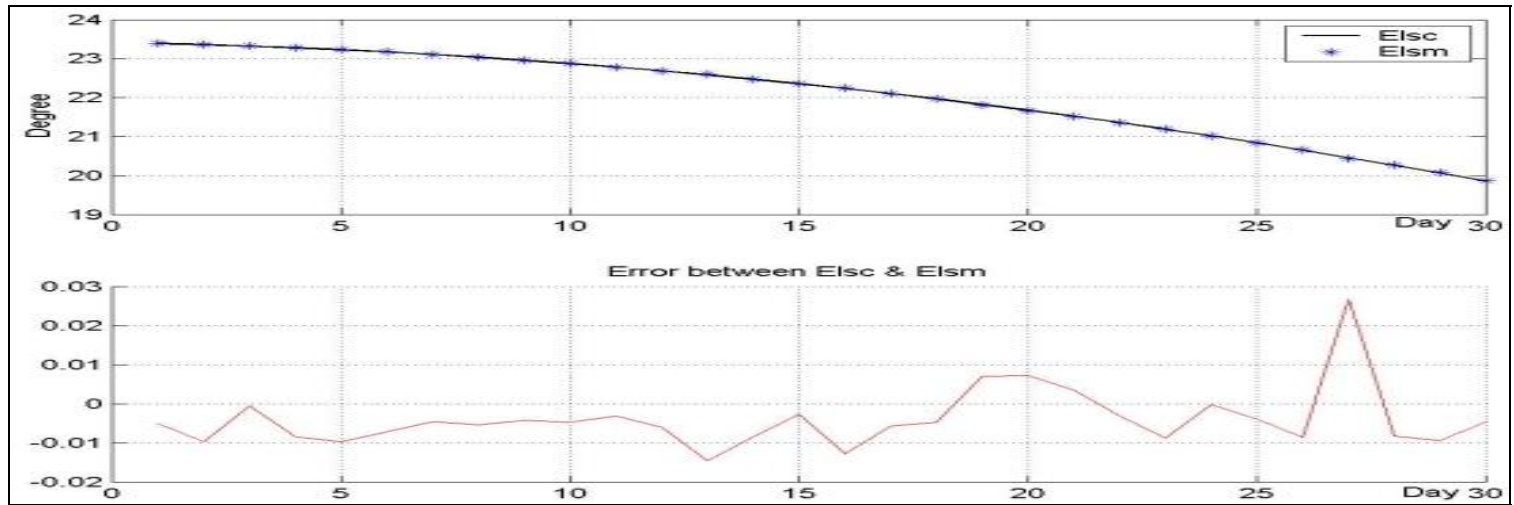

Fig.8 Elevation sun calculated vs. Elevation sun measured and the error between them.

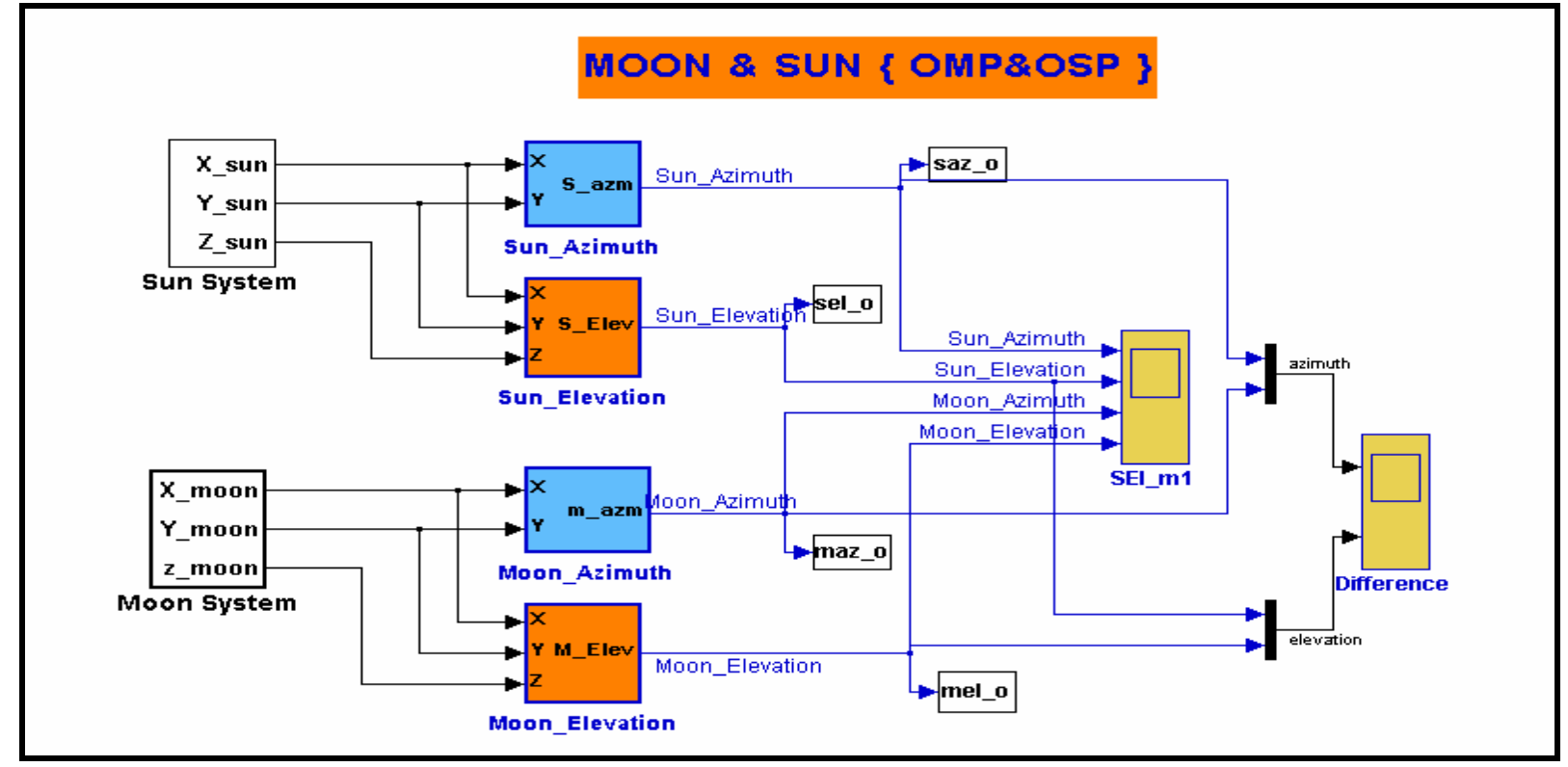

Fig.9 Linking between Moon system and Sun system.

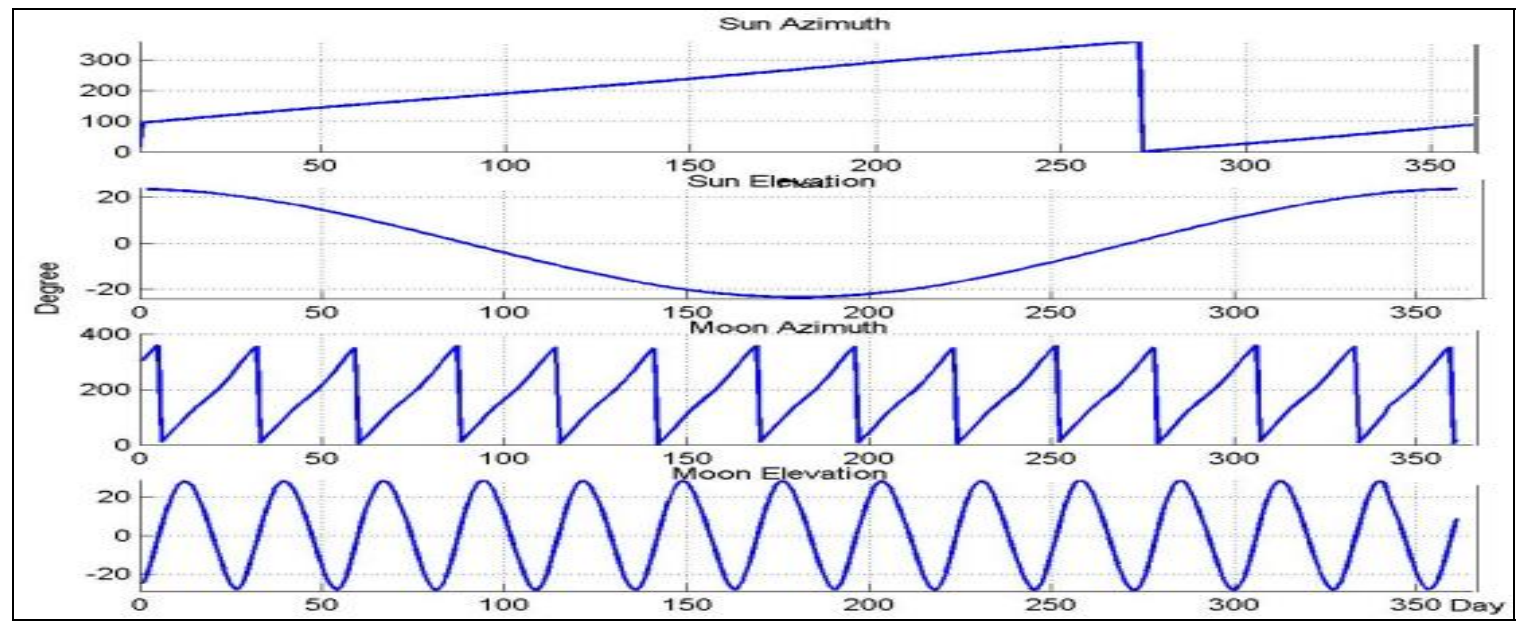

Fig.10 Sun azimuth, Sun elevation, Moon azimuth and Moon elevation related to the earth center from Moon and Sun Systems through 365 days. 

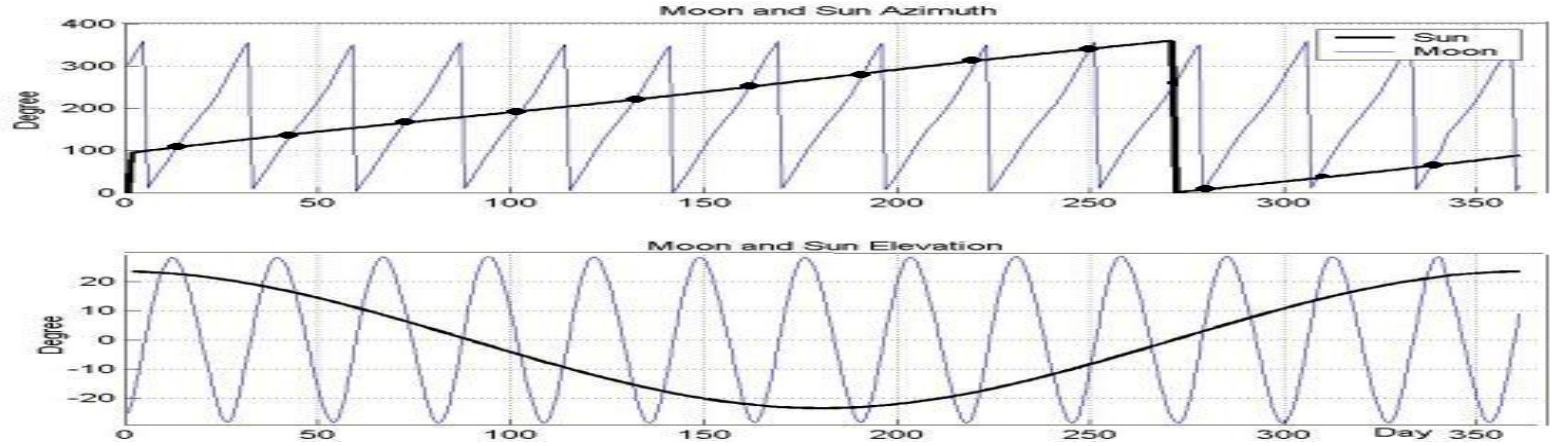

Fig.11 Moon and Sun azimuth for each day through one year, and also Moon and Sun elevation.

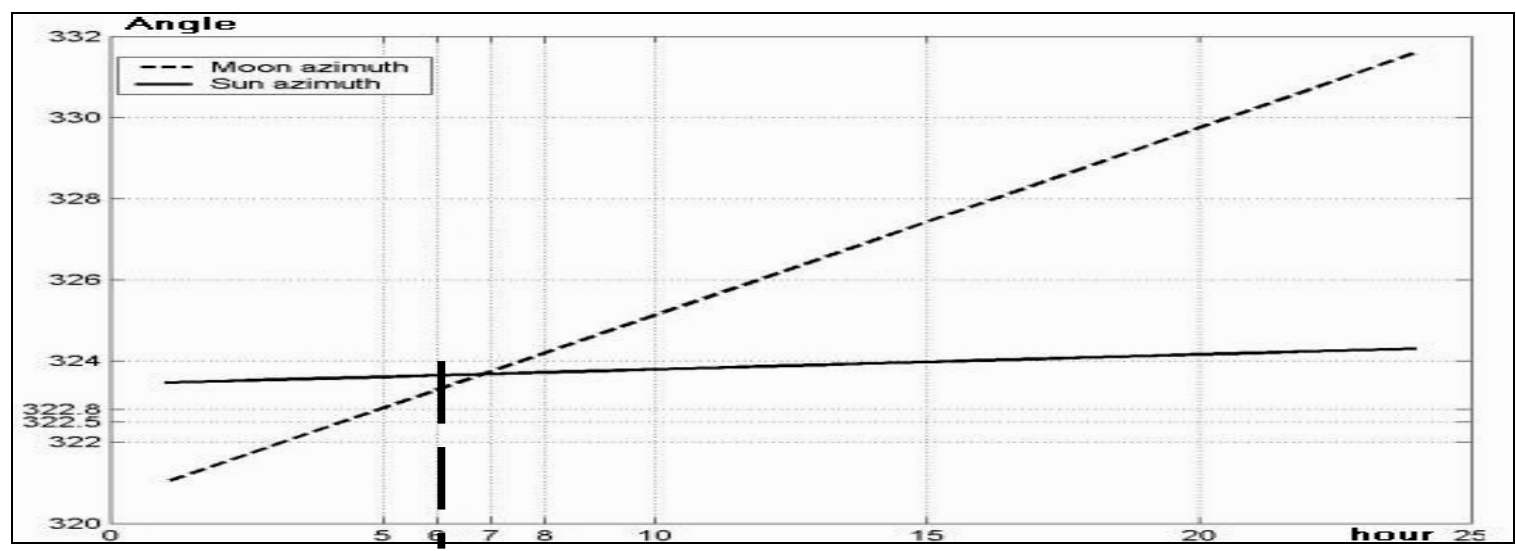

Fig.12 Moon and Sun azimuth at new moon birth through one day.

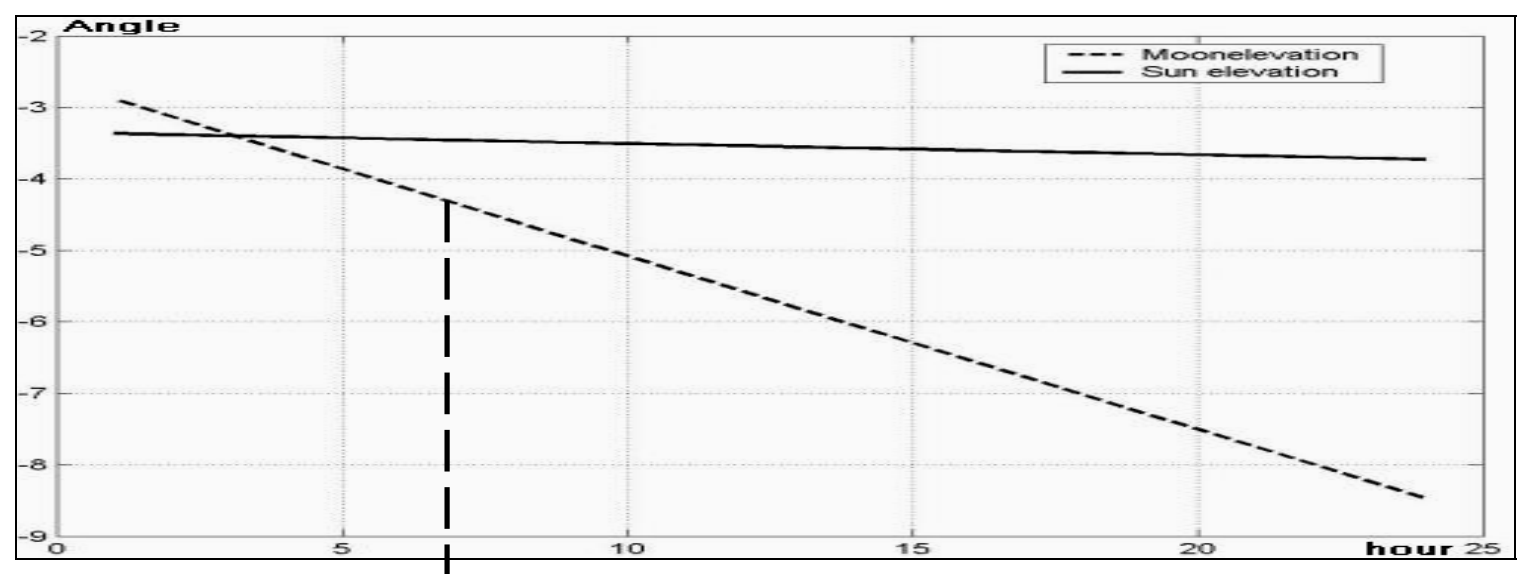

Fig.13 Moon and Sun elevation at new moon birth through one day. 


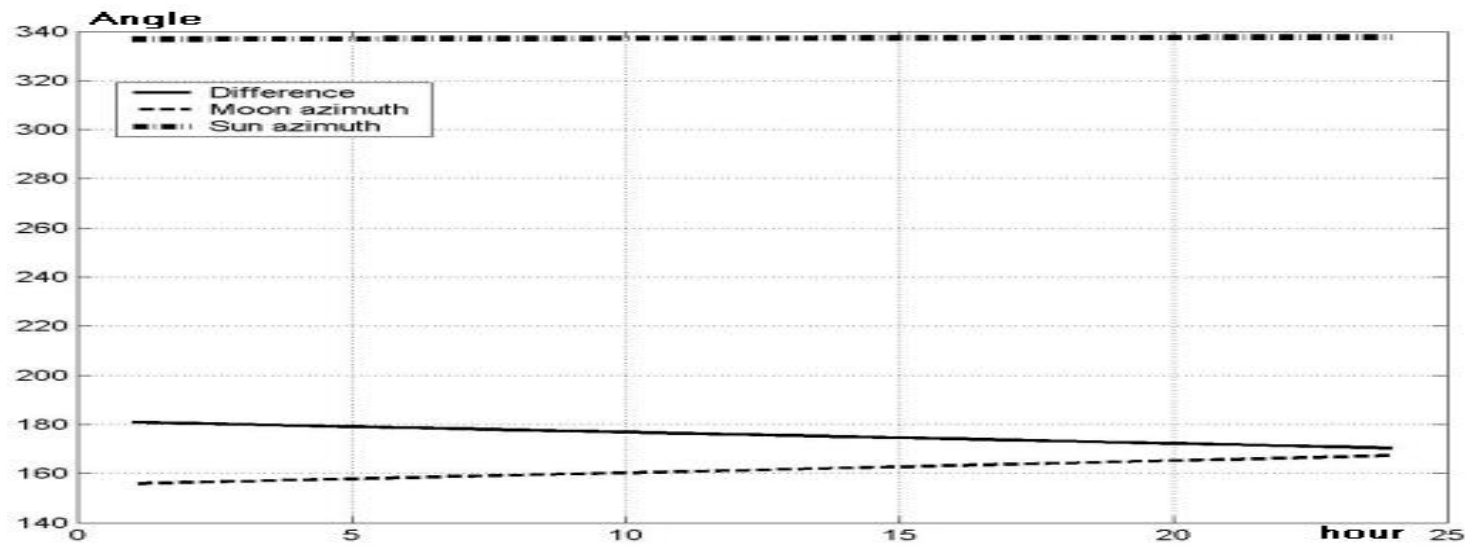

Fig.14 Difference between moon azimuth and sun azimuth equal to 180 at Full Moon.

\begin{tabular}{|c|c|c|c|c|c|c|c|c|}
\hline \multicolumn{4}{|l|}{ 睭 } & \multicolumn{5}{|c|}{ 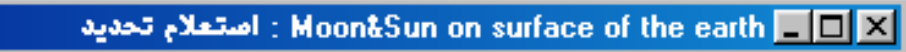 } \\
\hline$\Delta$ & day & time & Iongitude & latitude & sun_az & sun_ele & maz & mele \\
\hline ב & $27 / 06 / 05$ & $07: 30 \mathrm{am}$ & 45 & 45 & 67.23 & 3.083 & 276 & \begin{tabular}{|l|}
-58.31 \\
\end{tabular} \\
\hline & $27 / 06 / 05$ & $06: 30 \mathrm{am}$ & 30 & 45 & 67.1 & 3.18 & 297.6 & -66.33 \\
\hline & $27 / 06 / 05$ & 05:30 am & 15 & 45 & 66.98 & 3.28 & 328.46 & -69.4 \\
\hline & $27 / 06 / 05$ & $05: 30 \mathrm{am}$ & 15 & 30 & 66.8666 & 3.385 & 359.21 & -66.33 \\
\hline & $27 / 06 / 05$ & $06: 30 \mathrm{am}$ & 30 & 30 & 66.75 & 3.48 & 19.5 & -59.25 \\
\hline & $26 / 06 / 05$ & $05: 30 \mathrm{am}$ & 15 & 30 & 66.066 & 4.23 & 68.27 & 18.95 \\
\hline & $26 / 06 / 05$ & $05: 30 \mathrm{am}$ & 15 & 45 & 66.1166 & 4.13 & 63.25 & 8.87 \\
\hline-1 & $26 / 06 / 05$ & $06: 30 \mathrm{am}$ & 30 & 45 & 66.18 & 4.05 & 58.73 & -1.23[ \\
\hline & & & & & 270 & \begin{tabular}{l|l|l|} 
& \\
\end{tabular} & 1 & السجلا:||l|l| \\
\hline
\end{tabular}

Fig.15 Geographic data for moon and sun.

\begin{tabular}{|c|c|c|c|c|c|c|c|c|c|}
\hline \multicolumn{4}{|l|}{ 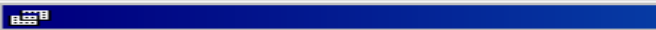 } & \multirow{2}{*}{$\frac{1}{m a x}=$} & \multirow{2}{*}{$\begin{array}{l}\text { Determine } \\
\text { time }\end{array}$} & \multirow[t]{2}{*}{ New } & Full & \multicolumn{2}{|c|}{ Moon $-|\square| x \mid$} \\
\hline-1 & Jay & شوع أهليد & $\operatorname{saz}$ & & & & & date & \\
\hline & 248 & New & 110.47537 & 110.42907 & 02:00 & am & & & \\
\hline & 248 & New & 110.51333 & 110.92788 & 03:00 & am & & & \\
\hline & 248 & New & 110.4374 & 109.92873 & 01:00 & 3 am & & $28 / 02 / 06$ & \\
\hline & 262 & Full & 123.78247 & 304.56817 & 11:00 & pm & & & \\
\hline & 262 & Full & 123.67225 & 303.16894 & ロ В: & p pm & & & \\
\hline & 262 & Full & 123.70899 & 303.63618 & 09:00 & pm & & & \\
\hline & 262 & Full & 123.74573 & 304.10258 & 10:00 & pm & & & \\
\hline & 262 & Full & 123.6355 & 302.70082 & $\square 7: 00$ & pm & & & \\
\hline & 277 & New & 136.67731 & 136.21046 & 04:00 & pm & & & \\
\hline & 277 & New & 136.75028 & 137.11745 & 口6:口ロ & pm & & & \\
\hline & 277 & New & 136.78677 & 137.57083 & $\square 7: 00$ & p pm & & & \\
\hline & 277 & New & 136.64082 & 135.7568 & 03:00 & 3 pm & & $29 / 03 / 01$ & \\
\hline & 277 & New & 136.71379 & 136.664 & 05:00 & 3 pm & & & \\
\hline & 292 & Full & 149.84438 & 330.08009 & $02: 00$ & 3 pm & & & \\
\hline & 292 & Full & 149.80715 & 329.61812 & 01:00 & p pm & & & \\
\hline-1 & 292 & Full & 149.88152 & 330.54276 & 03:00 & $2 \mathrm{pm}$ & & & \\
\hline & 4 & & $1>1$ & $91 \quad 0$ & $* 4|14| 4 \mid \Gamma$ & & $z$ & $\Rightarrow|-1|: L=$ & الdب \\
\hline
\end{tabular}

Fig.16 Spatial data at New moon birth. 


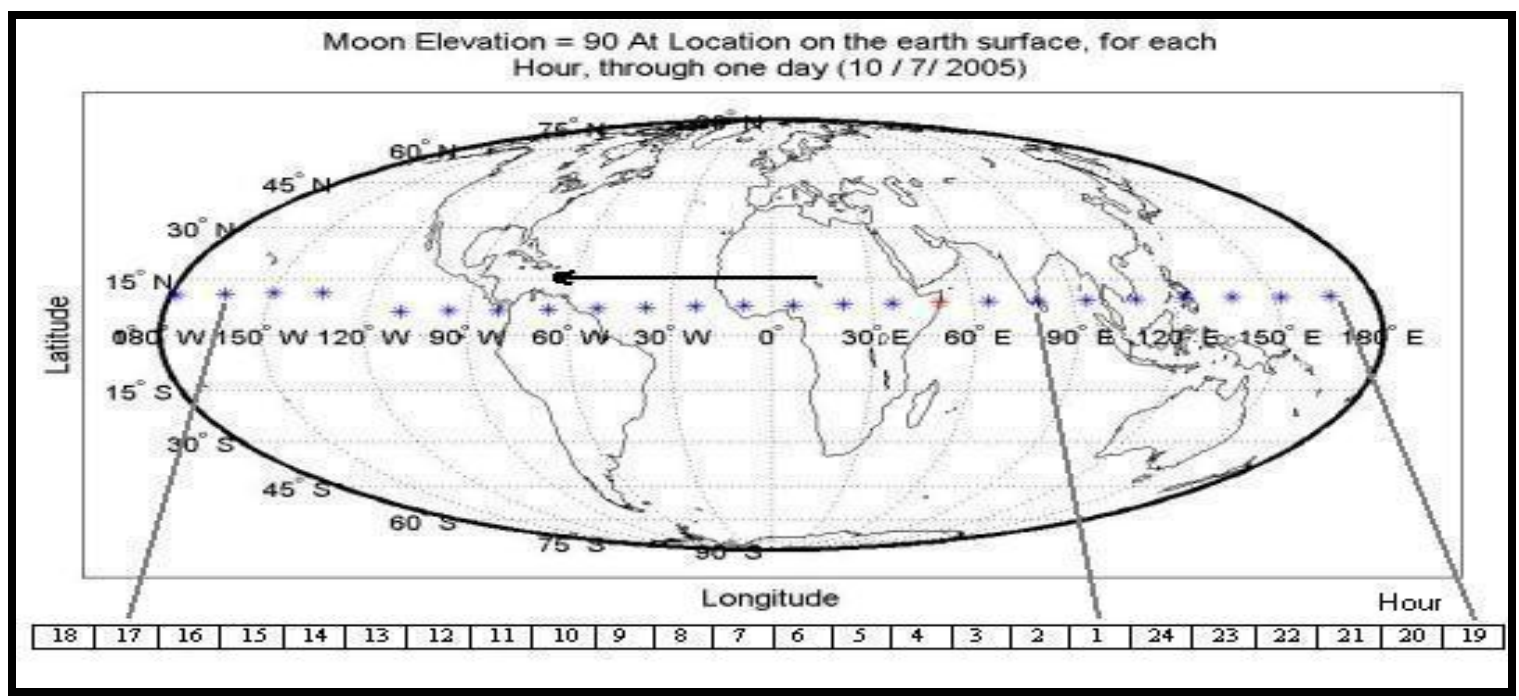

Fig.17 moon elevation $=90$ for one day

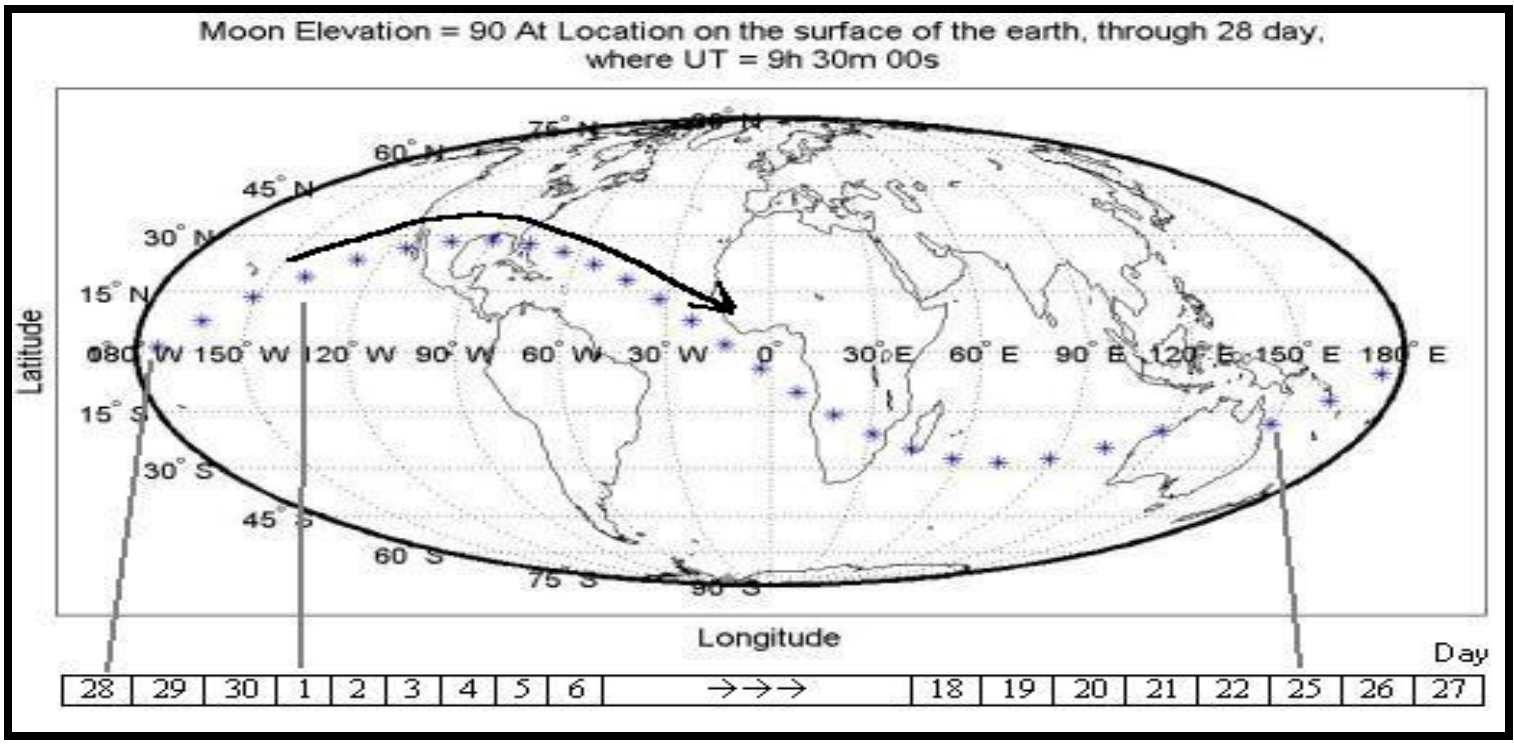

Fig.18 moon elevation $=90$ for one month 


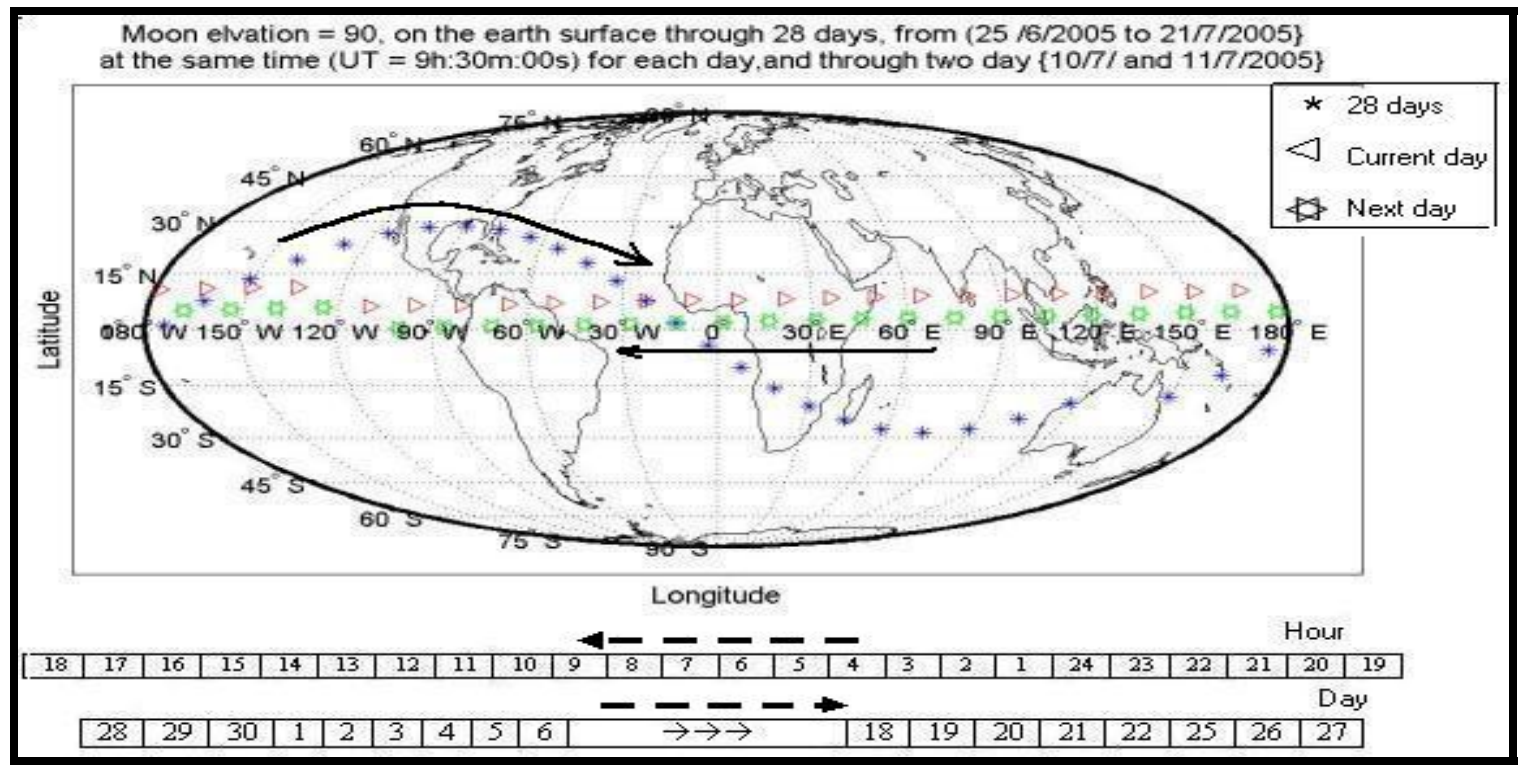

Fig.19 moon elevation =90 for two day and one month

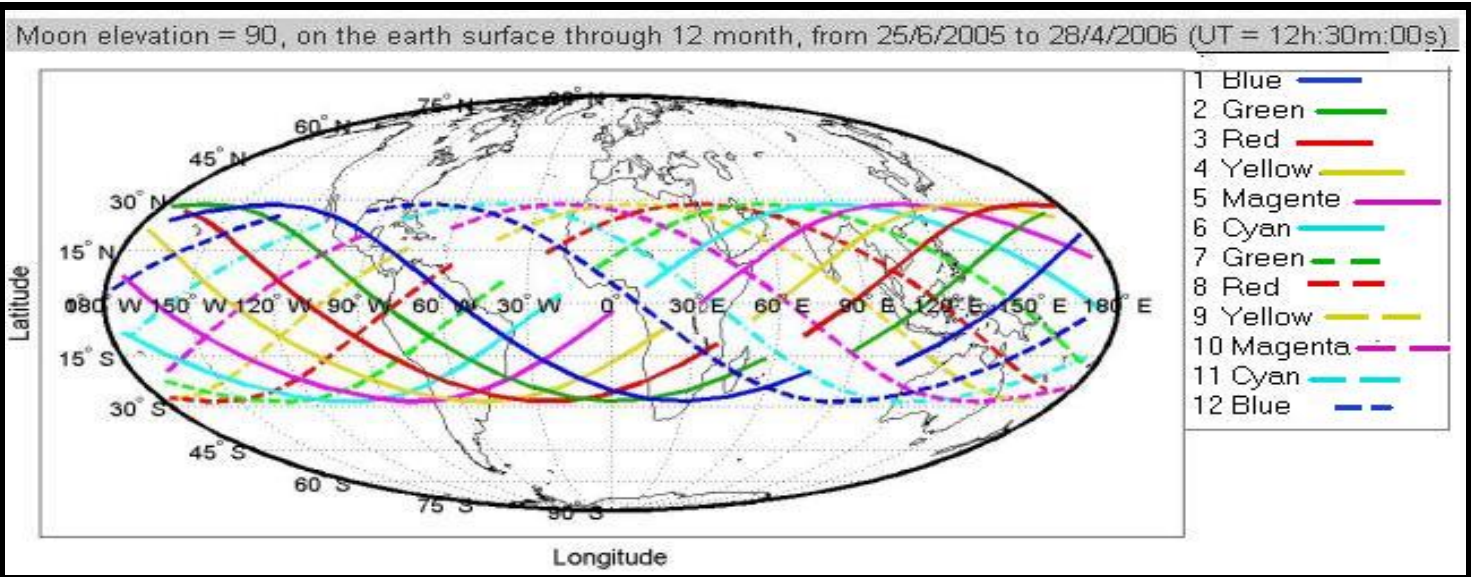

Fig.20 moon elevation $=90$ for 12 month

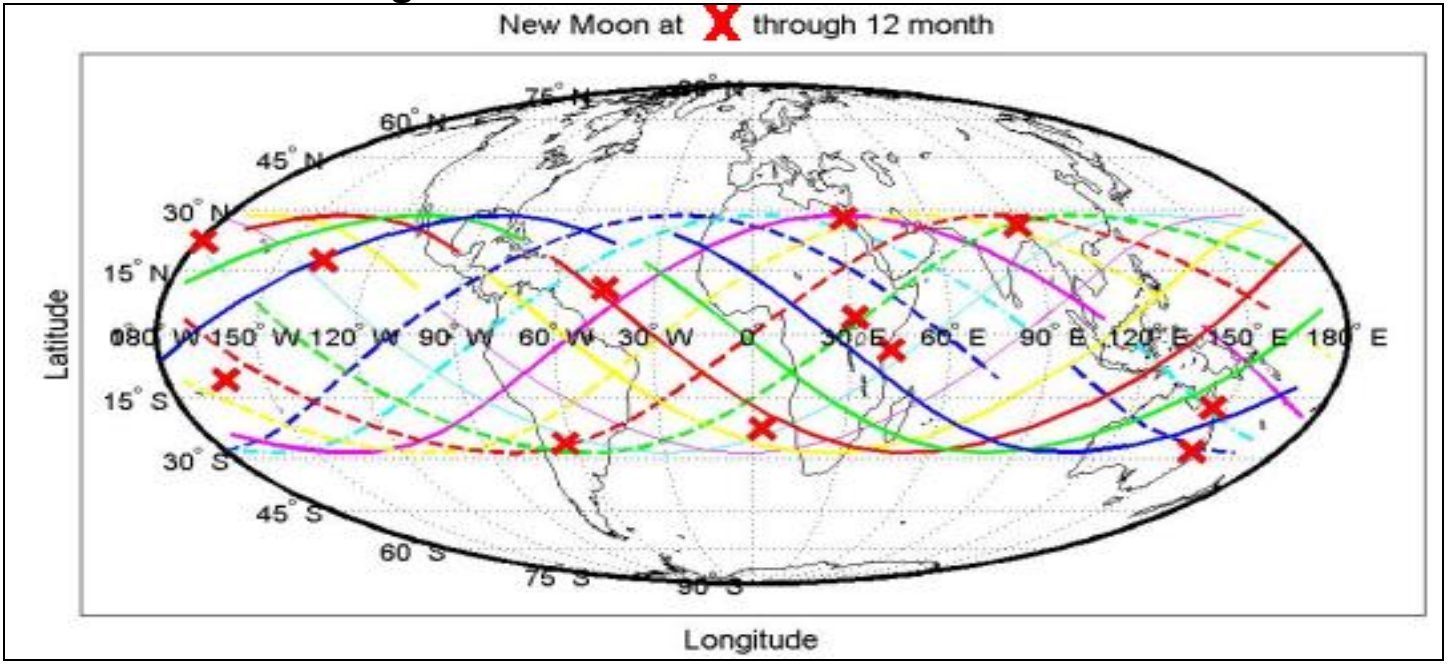

Fig.21 New moon through 12 month 


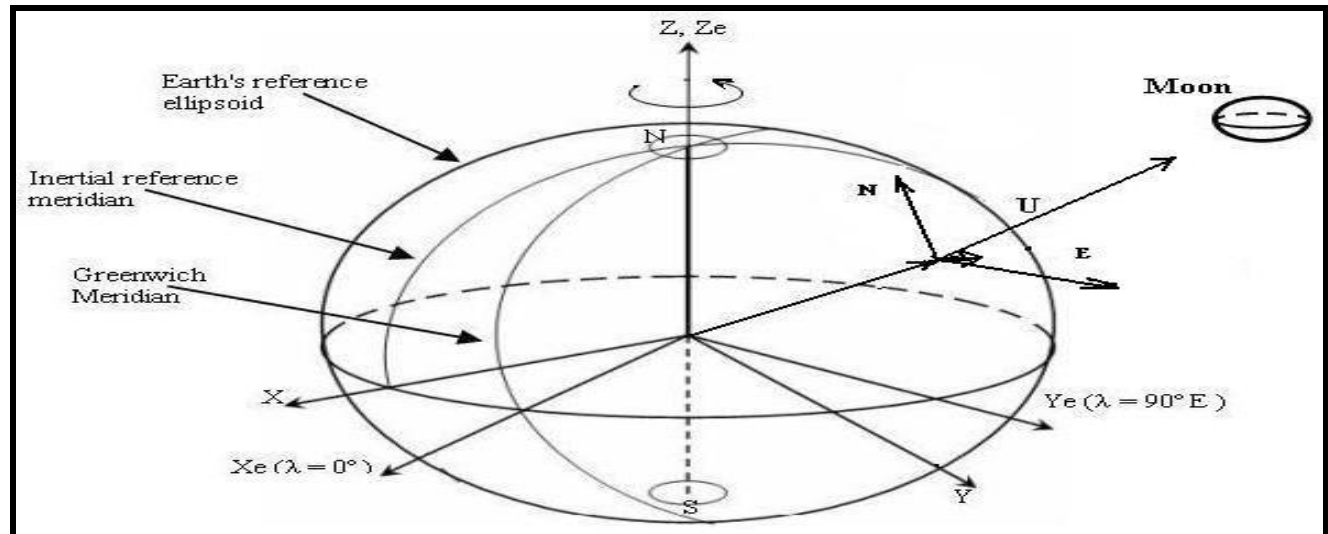

$X i, Y i, Z i$ or $X, Y, Z=$ inertial

$X e, Y e, Z e=$ earth-Fixed

$N, E, U$ or $X n, Y n, Z n=$ geographic ( or navigational frame)

Fig.22.a location of global view

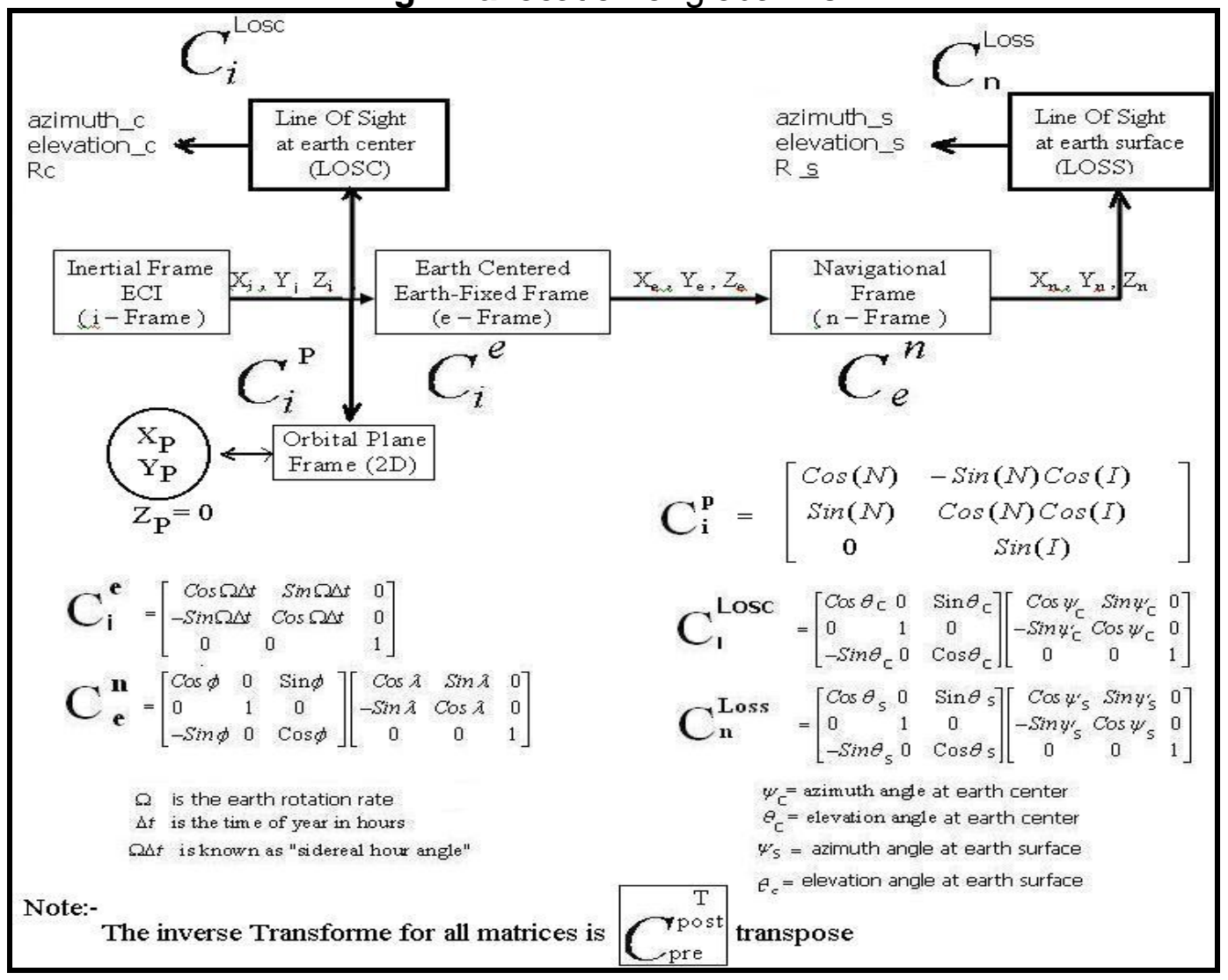

Fig.22.b Cosine Matrix transformations 


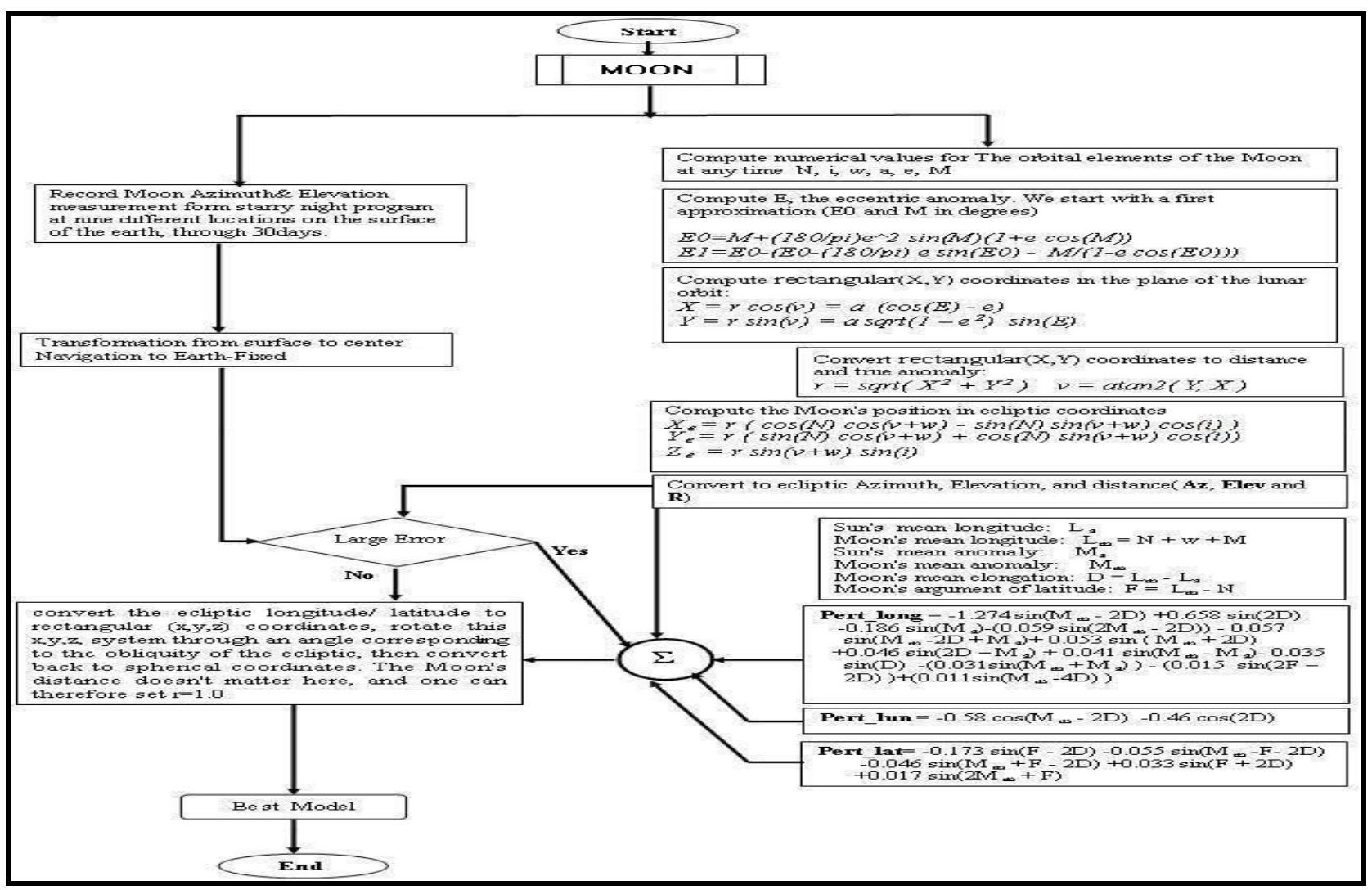

Fig .23 flow chart for computing moon position

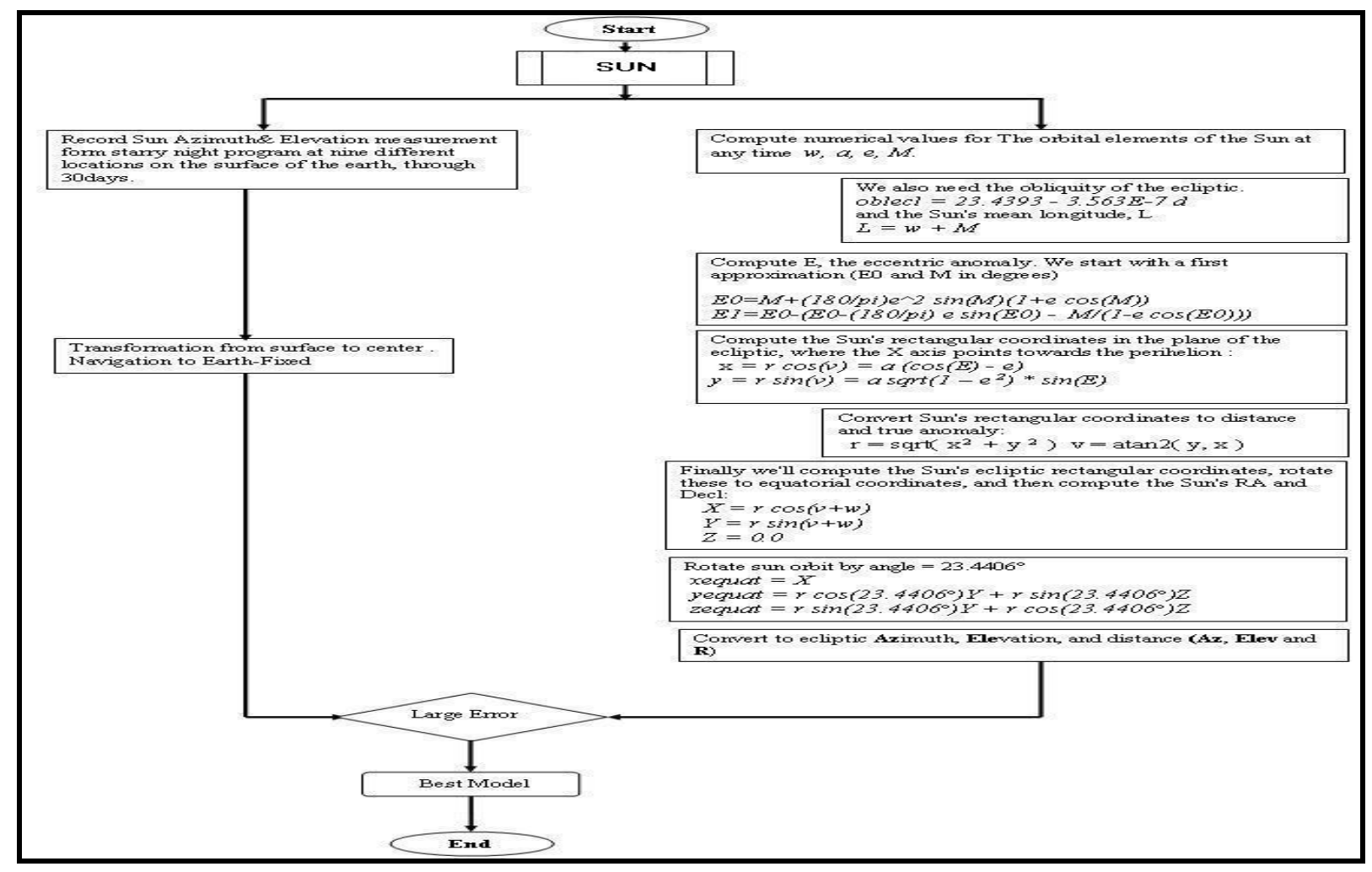

Fig .24 flow chart for computing sun position 